\title{
Financial System Architecture
}

\author{
Arnold W. A. Boot; Anjan V. Thakor \\ The Review of Financial Studies, Vol. 10, No. 3. (Autumn, 1997), pp. 693-733.
}

Stable URL:

http://links.jstor.org/sici?sici=0893-9454\%28199723\%2910\%3A3\%3C693\%3AFSA\%3E2.0.CO\%3B2-4

The Review of Financial Studies is currently published by Oxford University Press.

Your use of the JSTOR archive indicates your acceptance of JSTOR's Terms and Conditions of Use, available at

http://www.jstor.org/about/terms.html. JSTOR's Terms and Conditions of Use provides, in part, that unless you have obtained prior permission, you may not download an entire issue of a journal or multiple copies of articles, and you may use content in the JSTOR archive only for your personal, non-commercial use.

Please contact the publisher regarding any further use of this work. Publisher contact information may be obtained at http://www.jstor.org/journals/oup.html.

Each copy of any part of a JSTOR transmission must contain the same copyright notice that appears on the screen or printed page of such transmission.

The JSTOR Archive is a trusted digital repository providing for long-term preservation and access to leading academic journals and scholarly literature from around the world. The Archive is supported by libraries, scholarly societies, publishers, and foundations. It is an initiative of JSTOR, a not-for-profit organization with a mission to help the scholarly community take advantage of advances in technology. For more information regarding JSTOR, please contact support@ jstor.org. 


\title{
Financial System Architecture
}

\author{
Arnoud W. A. Boot \\ University of Amsterdam
}

\author{
Anjan V. Thakor \\ University of Michigan
}

This article builds a theory of financial system architecture. We ask: what is a financial market, what is a bank, and what determines the economic role of each? Starting with basic assumptions about primitives-the types of agents and the nature of informational asymmetries-we provide a theory that explains which agents coalesce to form banks and which trade in the capital market. It is shown that borrowers of higher observable qualities access the financial market. Moreover, a financial system in its infancy will be bank-dominated, and increased financial market sophistication diminishes bank lending.

A primary function of the financial system is to facilitate the transfer of resources from savers ("surplus

\footnotetext{
A. V. Thakor would like to thank the Edward J. Frey Chair in Banking and Finance for financial support. A. W. A. Boot thanks the Olin program in Law and Economics at Cornell University for its hospitality during part of the research on this article. The authors would also like to thank Todd Milbourn, Kathleen Petrie, and Anjolein Schmeits for excellent research assistance, and seminar participants at the University of Michigan, Indiana University, University of Amsterdam, Erasmus University, Rotterdam (the Netherlands), University of Minnesota, the JFI Symposium on Market Microstructure and the Design of Financial Systems at Northwestern University (May 1995), the Nordic Finance Symposium at Vendsnu, Norway (February 1995), Queen's University, Cornell University, the London School of Economics, the Stockholm School of Economics, the University of Goteborg (Sweden), McGill University (Canada), and participants at the CEPR meetings in St. Sebastian, Spain (April 1994), and Gerzensee, Switzerland (July 1994), and the American Finance Association meeting, San Francisco (January 1996) for helpful comments. The authors are particularly indebted to Ed Kane, Sudipto Bhattacharya, Paolo Fulghieri, Neil Wallace, Mike Stutzer, Franklin Allen (the editor), and an anonymous referee for helpful suggestions. Address correspondence to A. V. Thakor, University of Michigan Business School, 710 Tappan St., Ann Arbor, MI 48109-1234.
} 
units") to those who need funds ("deficit units"). In a well-designed financial system, resources are efficiently allocated. The question we address is, what is the configuration of such a financial system? In particular, we examine why bank lending and capital market financing coexist and the factors-such as regulation and the stage of economic development-that determine which dominates.

These issues are important for many of the current policy debates regarding the structuring of financial systems. How do banks and capital markets emerge and evolve? What services should be provided by banks and what services by the capital market? How is the resolution of informational problems related to how the financial system is configured?

These questions are particularly interesting in the context of Eastern European countries. The financial systems currently in place there are interim arrangements to facilitate transition to systems with lesser emphasis on the central planning of capital allocation [Checchi (1993)]. Although reform discussions have focused largely on the creation of financial markets [Mendelson and Peake (1993)], the more spectacular initial developments are likely to be in banking. For example, privately owned commercial banks were uncommon in Communist Europe until recently. Since then, however, banks have evolved rapidly [Perotti (1993) and Van Wijnbergen (1994)]. These developments point to a key aspect of financial system architecture: the determination of the roles of the banking system and the financial market.

Despite its importance, the research on this topic is still only emerging. Allen (1993) provides a qualitative assessment and sketches a preliminary framework for analysis. That article links financial system design to the complexity of decision making within firms seeking capital and provides a perspective on the disparate evolutions of financial markets in Europe and the United States. Bhattacharya and Chiesa (1995), Dewatripont and Maskin (1995), von Thadden (1995), and Yosha (1995) examine the comparative allocational efficiencies of "centralized" (bank-oriented) credit markets versus "decentralized" (market-oriented) credit markets. Somewhat different approaches are taken by Allen and Gale (1995, forthcoming) who suggest that bankoriented systems provide better intertemporal risk sharing, whereas market-oriented systems provide better cross-sectional risk sharing, and Sabani (1992) who argues that market-dominated economies will restructure financially distressed borrowers less than bank-dominated economies.

These contributions notwithstanding, there are unanswered questions. For example, how is the informativeness of market prices affected by financial system design? If unfettered by regulation, what determines the design of the financial system? And how does this de- 
sign affect the borrower's choice of financing source? Does financial system design have real effects?

This article is a modest first attempt to address these issues. We explain how financial institutions and markets form and evolve when economic agents are free to choose the way they organize themselves. Rather than taking the roles of institutions and markets as given and then asking how borrowers make their choice of financing source [e.g., Berlin and Mester (1992), Besanko and Kanatas (1993), Diamond (1991), and Chemmanur and Fulghieri (1994)], we start with assumptions about primitives - endowments and informational frictions-and endogenize the roles of banks and financial markets. The distinction we make between a bank and a market is that agents within a bank can cooperate and coordinate their actions, whereas agents in a market compete ${ }^{1}$ we assume nothing more about what banks and markets do.

We begin by positing three types of informational problems: (i) incomplete information about future projects that is of relevance for firm valuation and real investment decisions within firms, (ii) postlending (asset substitution) moral hazard that can affect payoffs to creditors, and (iii) uncertainty about whether postlending moral hazard will be encountered. Part of the primitives are economic agents who specialize in resolving these informational problems, with each individual agent being atomistic in impact. Our first major result is that problem (i) is most efficiently resolved in an "uncoordinated" market setting where individual agents compete with each other, and problems (ii) and (iii) are most efficiently resolved through coordinated action by agents coalescing to form a bank. The scope of banking vis-a-vis the financial market is thereby determined endogenously in an unregulated economy in which the financial market is characterized by many agents and a rational expectations equilibrium price formation process that noisily aggregates information contained in the order flows for securities. A key attribute of the financial market, and one that delineates its role from that of a bank, is that there is valuable information feedback from the equilibrium market prices of securities to the real decisions of firms that impact those market prices. $^{2}$ This information loop provides a propagation mechanism by which the effects of finan-

\footnotetext{
${ }^{1}$ Perhaps an even more basic distinction is that agents can be anonymous in a market but not in institutions. This may be a way to rationalize the possibility of coordination within a bank and the lack of it in an anonymous, competitive market setting.

${ }^{2}$ Allen (1993) suggests that an important role of the stock market is to provide decision-makers in firms with information they would not otherwise have possessed. Holmström and Tirole (1993) examine the role of the stock market as a monitor of managerial performance. They show that a firm's stock price incorporates performance information that cannot be gleaned from the firm's current or future profit data, and that this information is useful in structuring managerial incentives.
} 
cial market trading are felt in the real sector. Bank financing does not have such an information loop. Hence, real decisions are not impacted by the information contained in bank credit contracts. However, banks are shown to be superior in resolving asset substitution moral hazard. Thus, in choosing between banks and financial markets, one trades off the improvement in real decisions due to feedback from market prices against a more efficient attenuation of moral hazard.

The relative levels of credit allocated by banks and the financial market depend on the efficacy of the bank's monitoring and the "development" (i.e., sophistication or level of financial innovation) of the financial market. We let the latter be reflected in the information acquisition cost for those who wish to become informed. We show that the cost of information acquisition affects the informativeness of equilibrium security prices, and therefore the relative scopes of banks and the financial market in credit allocation. In describing these scopes, our article explains:

- why banks emerge even when every agent in a bank could trade on his own in the market;

- why financial markets develop even when there are no restrictions on banks' activities;

- why a financial market equilibrium in which prices convey information can exist only if prices do not have too much or too little informativeness; ${ }^{3}$

- why borrowers prefer either the financial market or banks based on differences in observable borrower attributes; ${ }^{4}$

- how financial market trading affects firms' real decisions;

- how the state of development of the financial market can impact the borrower's choice of financing source.

The rest of the article is organized as follows. Section 1 contains a description of the basic model. Section 2 analyzes the formation of banks and the financial market. Further analysis is contained in Sections 3 and 4 . Section 5 examines model robustness issues. Section 6 explores the implications of the analysis for financial system design. Section 7 concludes. All proofs are in the Appendix.

\footnotetext{
3 This is in contrast to the existing literature in which the value of information acquisition is nondecreasing the noisiness of the process by which information is aggregated le.g., Grossman and Stiglitz (1980)].

${ }^{4}$ Since banks resolve moral hazard in our model, the bank's decision to grant a loan does not trigger an abnormally positive reaction in the borrower's stock price as found empirically by James (1987), Lummer and McConnell (1989), and Shockley and Thakor (1996, forthcoming). Of course, if our model were to be altered to introduce uncertainty about whether the borrower would have a project available, then the bank's decision to grant a loan would signal good news. See Boot and Thakor (1996, forthcoming) for such an approach.
} 


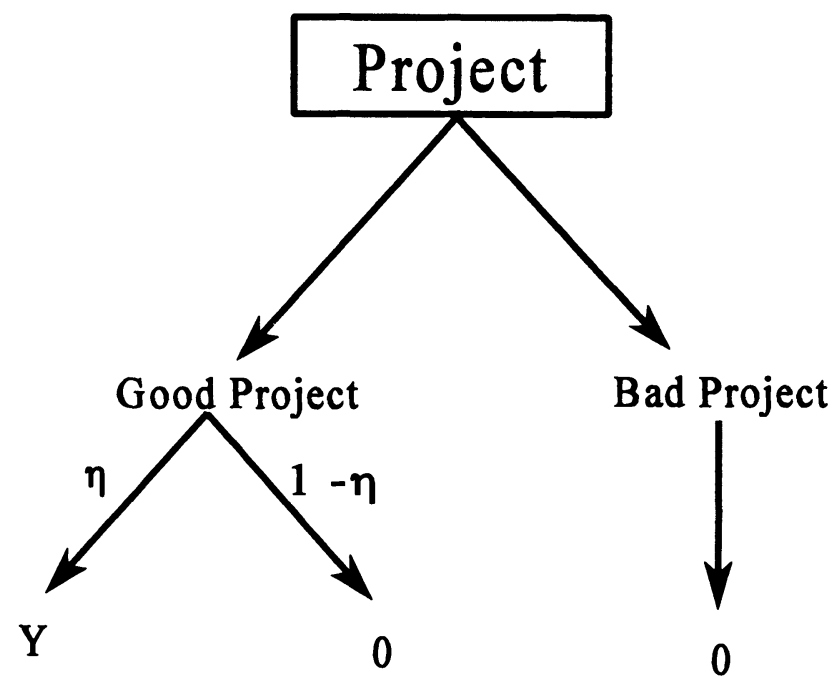

Figure 1

A Schematic of the types of projects (without payoff enhancement) and contractible returns

\section{The Basic Model}

\subsection{Production possibilities for firms}

1.1.1 Preferences and types of projects. There is universal risk neutrality, and the riskless interest rate is zero. The economy consists of firms each with a project that needs a $\$ 1$ investment. As shown in Figure 1, each firm has a stochastic investment opportunity set that contains two projects: good and bad. The contractible end-ofperiod return for the good project has a probability distribution with a two-point support: with probability $\eta$ the end-of-period return will be $Y>0$, and with probability $1-\eta$ it will be 0 . The contractible end-of-period return for a bad project will be 0 with probability 1 , but this project offers the borrowing firm's manager a noncontractible private rent, $N$, from investing in the project [see, e.g., O'Hara (1993)]. Let $\eta Y>N$, so that the borrower prefers the good project with selffinancing.

\subsubsection{Project availability and payoff enhancement possibility.} Project availability is stochastic. With probability $\theta \in(\underline{\theta}, \bar{\theta}) \subset(0,1)$, the firm finds itself in the "low flexibility" (LF) state in which it has only the good project available. With probability $1-\theta$, the firm finds itself in the "high flexibility" (HF) state and has both the good and the bad project available. 


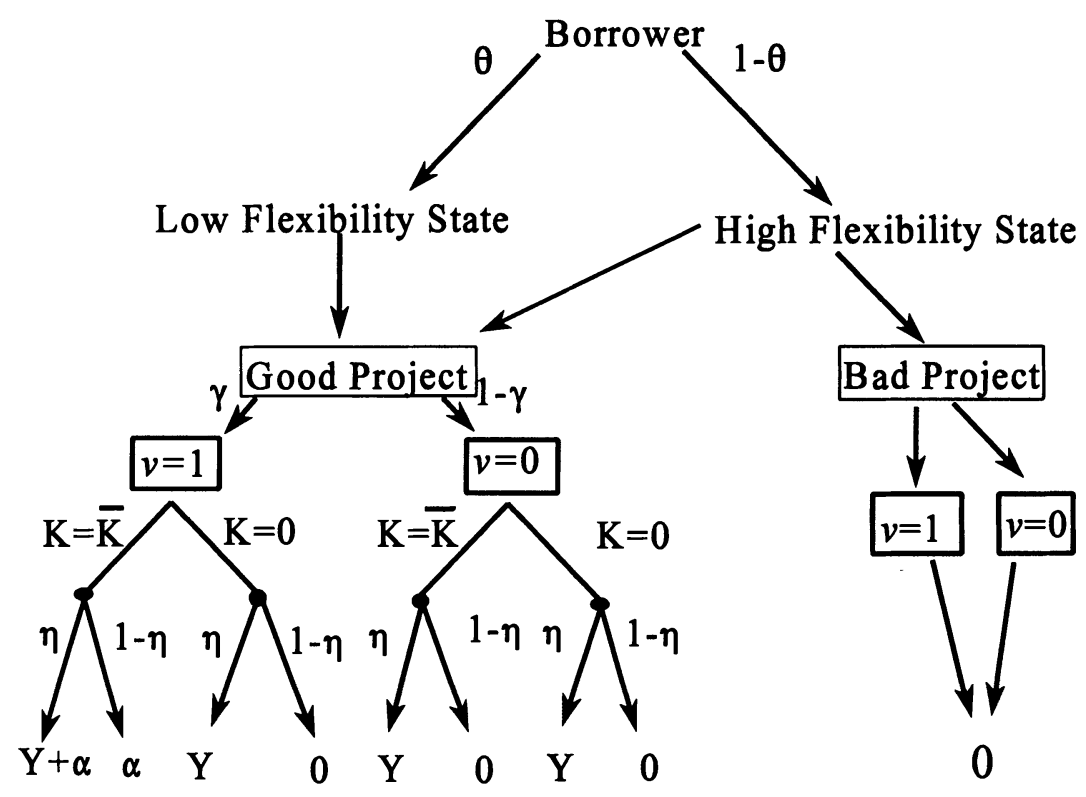

Figure 2

A schematic of the types of projects (with payoff enhancement) and contractible returns

We assume that the firm can possibly enhance the return of the good project at a private cost of $K=\bar{K}>0$, where $K \in\{0, \bar{K}\}$. This investment is unobservable to outsiders, and it enhances the project return by $\alpha \in(0,1)$, conditional on a favorable realization of an "environmental" or "market" random variable $v \in\{0,1\},{ }^{5}$ with $\operatorname{Pr}(v=1)=\gamma \in(0,1)$ as the probability that the a priori uninformed assign to the event that $v=1$. Let $\alpha>\bar{K}$. Note that $v$ is specific to each firm rather than being an economywide variable. Thus, if $v=1$ and the firm invests $K=\bar{K}$, then the good project pays off $Y+\alpha$ with probability $\eta$ and $\alpha$ with probability $1-\eta$. If a borrower invests $K=0$, then the good project's return is $Y$ with probability $\eta$ and 0 with probability $1-\eta$, regardless of $v$. If a borrower invests either $K=\bar{K}$ or $K=0$ in a bad project, the contractible project return is 0 with probability 1 , regardless of $v$. Thus, the improvement in the project return depends on borrower-specific investments as well as the realization of exogenous uncertainties like market demand (see Figure 2).

\footnotetext{
${ }^{5}$ It does not matter much if we assume that $K$ is observable to outsiders. With $K$ unobservable, the firm underinvests relative to first best, whereas with $K$ observable, there is no underinvestment.
} 
We assume that the realization of $v$ can only be observed by those who become informed at a cost; we will say more about this later. For now, it suffices that the borrower cannot observe $v$, but believes that $\operatorname{Pr}(v=1)=\gamma$. This belief is common knowledge. If the borrower is uninformed about $v$, an investment $K=\bar{K}>0$ is suboptimal. That is, we assume $\gamma \alpha-\bar{K}<0$, where $\gamma \alpha$ is the expected project enhancement if the borrower is uninformed about $\nu$. We assume $\eta>\gamma$ and that

$$
\gamma \alpha<\bar{K}<\eta \alpha
$$

Further, we assume that exogenous parameter values are such that there exists an interest factor (one plus the interest rate) $r^{0}<1$ satisfying $\eta\left[Y+\alpha-r^{0}\right]-\bar{K}=N$.

Given this, the firm prefers the bad project with external financing if the interest factor exceeds $r^{0}$, and it prefers the good project with external financing if the interest factor is less than $r^{0}$. Since $r^{0}<1$ and we had earlier assumed that $\eta Y>N$, the firm always prefers the good project with self-financing and the bad project with external financing. From the lender's standpoint, therefore, there is asset-substitution moral hazard only in the HF state. We view the parameter $\theta$ as the commonly known prior probability assigned by the market to the event that a randomly selected borrower will be in the LF state and hence pose no moral hazard. Each potential borrower is characterized by its observable $\theta \in(\underline{\theta}, \bar{\theta})$. Let $H$ be the cumulative distribution function over the cross-section of $\theta \mathrm{s}$.

\subsection{Types of securities}

We limit financiers to debt contracts. This is primarily because bank lending is typically done through debt contracts, and we want to have comparability between the bank and capital market financing cases. Thus, the capital market financing in our model is through bonds. Of course, information acquisition in bond markets is probably smaller than that in the stock market. It is therefore important to note that our analysis understates the information acquisition benefits of financial markets, but is qualitatively unaffected if debt is replaced by equity (see Section 5).

\subsection{Sequence of events in lender-borrower interaction}

The firm first makes an irreversible decision about whether to borrow from a bank or the financial market. At this stage the only information that it has is about its $\theta$, and this information is common knowledge. ${ }^{6}$ 


\begin{tabular}{|c|c|c|c|}
\hline $\mathbf{t}=\mathbf{0}$ & $t=1$ & $t=2$ & $\mathbf{t}=\mathbf{3}$ \\
\hline $\begin{array}{l}\text { - Each firm's } \theta \text { is } \\
\text { common knowledge. } \\
\text { - Each firm makes an } \\
\text { irrevocable decision } \\
\text { of whether to borrow } \\
\text { from a bank or in the } \\
\text { financial market. } \\
\text { - Traders decide } \\
\text { whether to become } \\
\text { monitoring agents, } \\
\text { informed agents or } \\
\text { remain uninformed } \\
\text { discretionary traders. } \\
\text { The informed agents } \\
\text { invest } M \text { to acquire } \\
\text { their information. } \\
\text { - Banks are formed. }\end{array}$ & $\begin{array}{l}\text { Firm learns whether it } \\
\text { is in the LF or the HF } \\
\text { state, after which } v \text { is } \\
\text { privately learned by } \\
\text { informed traders. } \\
\text { - Different types of } \\
\text { traders anonymously } \\
\text { submit their purchase } \\
\text { orders for the firm's } \\
\text { securities to the market } \\
\text { maker in the financial } \\
\text { market. } \\
\text { - A price for the firm's } \\
\text { debt is determined } \\
\text { either in the financial } \\
\text { market or by a bank. }\end{array}$ & $\begin{array}{l}\text { The firm borrows } \$ 1 \\
\text { to invest in its project. } \\
\text { - The firm infers } v \\
\text { from its financial } \\
\text { market price and } \\
\text { decides whether to } \\
\text { invest } K \text { or } 0 \text { in project } \\
\text { payoff enhancement. } \\
\text { - If the firm is in the } \\
\text { HF state and the lender } \\
\text { can monitor the project } \\
\text { choice, it will ensure } \\
\text { that the firm chooses } \\
\text { the good project. Each } \\
\text { agent in the lender } \\
\text { coalititon incurs } \\
\text { monitoring cost } M \\
\text { regardless of the state } \\
\text { the borrower is in. }\end{array}$ & $\begin{array}{l}\text { - The firm's project } \\
\text { payoff is realized. } \\
\text { - Lenders are paid } \\
\text { off if the project } \\
\text { payoff permits it. }\end{array}$ \\
\hline
\end{tabular}

organizes for trading.

Figure 3

A description of the sequence of events in the economy

Subsequently, the firm learns whether it is in the LF or the HF state, and after this $v$ is realized and learned by those who choose to become informed about it. The lender (either the bank or the financial market) offers a price of credit that the firm can either accept or respond to with a take-it-or-leave-it counteroffer. Moreover, based on the lender's actions (the offered credit price or the market demand for the firm's security in the financial market), the firm makes its inference about the realization of $v$. Next, the firm makes its initial choice of project if it is in the HF state; in the LF state, this choice is trivially the good project. If the lender can observe this initial choice and monitor, it can force a change to the good project in the event that the firm had initially chosen the bad project. This leads to the firm's final project choice decision and its investment of $\$ 1$ in the project. Moreover, at this time the firm also makes its decision regarding investing $K \in\{0, \bar{K}\}$ for project payoff enhancement (see Figure 3).

\footnotetext{
${ }^{6}$ We assume that the firm commits to a financing choice at the outset to avoid the situation in which financial market investors produce information about a firm that ends up borrowing from a bank. Although in equilibrium each firm's choice of financing source is unambiguously linked to its $\theta$, and this $\theta$ is commonly known at the outset. What we wish to avoid is the firm learning about $v$ from its market price (which is based on investors erroneously believing that the firm will borrow in the financial market) and then borrowing from a bank.
} 


\subsection{Types of agents in the economy}

The structure for the financial market is as follows. ${ }^{7}$ There are two types of investors/traders in the market: liquidity traders and discretionary agents. The aggregate asset demand, $\ell$, of the liquidity traders is random and exogenously specified by the continuously differentiable probability density function $f(\ell)=A-\frac{A^{2} \ell}{2}$, where $A$ is a positive constant. Thus, the support of $f(\ell)$ is $[0,2 / A]$. A discretionary agent can become an "informed" or a "monitoring" agent at a finite cost $M>0$. This investment $M$ either generates a signal that perfectly reveals the $v$ for the firm in question or enables the agent to monitor the firm's investment choice between the good and the bad project. The discretionary agent must decide before investing $M$ whether she wishes to be an informed agent and receive the signal or become a monitoring agent. If the discretionary agent does not invest $M$, she can be an uninformed discretionary trader who can either invest in the capital market or in bank deposits.

We will first focus on agents who become informed about $v$. Each submits a demand order $d_{I}$. Let us conjecture that the equilibrium strategy of an informed trader is to set $d_{I}=1$ if the signal says $v=1$ and $d_{I}=0$ if the signal says $v=0$; we will validate this conjecture later. Each trader is very small but of $\epsilon>0$ Lebesgue measure on the real line. We will focus on the limiting case in which $\epsilon \rightarrow 0$ so that each trader is atomistic, and all traders lie in a continuum. Let $\Omega$ be the (Lebesgue) measure of informed traders, with each submitting a demand of 0 or 1 . The total informed demand is therefore $D_{I}=\Omega d_{I}$.

Liquidity traders' demand is not information driven and is based on exogenous factors outside the model. All demand orders are submitted to a market maker, and informed and liquidity traders are observationally identical to the market maker. Thus, the market maker observes only the total demand, $D=D_{I}+\ell$, and not its individual components, $D_{I}$ and $\ell$. The supply of the (debt) security is fixed at $\$ 1$. We assume that there is a sufficient number of "professional" market makers, so that the market is competitive. The market maker receives all the orders for a given security and takes the position in the security required io clear the market at a price that yields her zero expected profit, conditional on the information in the order flow. Thus, the market maker takes a long position in the security if supply exceeds demand and a short position if demand exceeds supply. The debt security in question is a bond issued at par, and the price set by the market maker is the bond's coupon rate (or interest rate).

\footnotetext{
${ }^{7}$ This structure is similar to that in Boot and Thakor (1993a), but richer in that agents can also choose to monitor and there is information feedback from the financial market to the firm.
} 
If the discretionary agent becomes a monitoring agent, she has the ability to monitor the borrower and detect its choice of the bad project; allowing this detection to be noisy is inconsequential. However, since each agent is atomistic, the borrower cannot be prevented from choosing the bad project unless a sufficiently large measure of monitoring agents is involved. ${ }^{8}$ We assume that the minimum measure of monitoring agents needed to deter the borrower is $\Lambda^{*}<1$. Moreover, while the discretionary agent decides at the outset whether to be an informed trader or a monitoring agent, the actual expense, $M$, of a monitoring agent, is not incurred until after a loan has been extended to the borrower, whereas the outlay of $M>0$ by an informed trader occurs prior to her placing her order for the security. This distinguishes information acquisition from postlending monitoring. For later use, we assume

$$
\bar{\theta}\left[1+\Lambda^{*} M\right]-1<0
$$

This ensures that lending without monitoring and information acquisition is unprofitable, even if the promised interest rate is grossed up to compensate for anticipated monitoring expenses. To understand Equation (2) intuitively, note that the following two conditions are sufficient (but not necessary) to obtain Equation (2): (i) $\bar{\theta} \eta Y<1$, which implies that an unmonitored project has a negative net present value (NPV), and (ii) $\eta Y>1+\Lambda^{*} M$, which implies that a monitored project has a positive NPV.

\section{The Emergence of Banks and the Capital Market}

\subsection{Definitions of markets, institutions, and the overall equilibrium}

A financial market is a collection of traders who all compete to buy debt securities offered by borrowing firms, and where the equilibrium security price is determined through a Walrasian market clearing condition enforced by a market maker. A bank is a collection of traders who coalesce to form an institution, provide deposit funding, and coordinate their actions with respect to the borrower. In an interior equilibrium, discretionary agents must be indifferent between becom-

\footnotetext{
${ }^{8}$ The idea is that an individual bondholder who has purchased a $\$ 100$ bond as part of a $\$ 50$ million IBM bond issue can do little to influence the firm's project choice. However, collectively-as with bank lending - the bondholders who purchased all of IBM's bonds could dictate a lot. Even when a borrower is solvent, "large block" creditors (either coalitions of bondholders who own significant portions of the firm's public bonds or institutional lenders like banks) can influence specific aspects of a firm's investment policy for reasons related to the borrower's desire to maintain a good relationship with the lender and retain operating flexibility when temporary negative shocks to cash flows elevate the risk of covenant violations.
} 
ing informed traders, monitoring agents, or uninformed discretionary traders/depositors. ${ }^{9}$ Since the expected equilibrium profit from being an uninformed discretionary trader/depositor is zero, informed traders and monitoring agents must also earn zero expected profit in equilibrium.

\subsection{Discretionary agents' choices}

Consider discretionary agents who have chosen to become informed traders. Each now stands ready to receive a signal about $v$. They must decide whether to compete with others in the market in bidding for a debt security or coalesce into a bank and coordinate their actions.

Lemma 1. Those who invest $M$ to become informed traders will prefer to compete with each other as financial market traders rather than become bankers.

The monitoring agents must make a similar choice.

Lemma 2. Those who invest $M$ to become monitoring agents willprefer to coalesce to form a bank and coordinate their actions in monitoring the borrower. Moreover, the measure of monitoring agents in the bank will be exactly $\Lambda^{*}$, the minimum needed to deter the firm from choosing the bad project.

Given Lemma 1, we see that the financial market will consist of informed traders and liquidity traders. While the informed traders' demand is endogenously determined and the liquidity traders' demand is exogenous, it is possible that their total demand is not equal to 1 , the available supply of the security. We assume that some of the uninformed discretionary traders in the market form coalitions called "market makers," each of whom is forced by competition to earn zero expected profit and "correct" the demand-supply imbalance by taking an appropriate position in the security. Moreover, given Lemma 2, the equilibrium measure of monitoring agents equals $\Lambda^{*}<1$. Thus, some uninformed discretionary traders join the bank as nonmonitoring depositors and provide the remaining funding, $1-\Lambda^{*}$. Combining Lemmas 1 and 2 yields the next observation.

Proposition 1. In equilibrium, the financial market consists of informed traders, uninformed discretionary traders, and liquidity traders. The informed traders are the only ones who learn $v$, and their trades have the potential to convey this information. The financial mar-

\footnotetext{
${ }^{9}$ We will assume throughout that the costs of becoming informed and monitoring agents are such that an interior equilibrium obtains. It is possible, however, that if these costs are sufficiently high, all traders may strictly prefer to remain uninformed and the measures of informed and monitoring agents are zero.
} 
ket is ineffective, bowever, in deterring borrowers from investing in the bad project when they have the choice. In equilibrium, banks consist of monitoring agents and uninformed discretionary agents who act as nonmonitoring depositors. The bank specializes in deterring borrowers from investing in bad projects, but it learns nothing about $v$.

The intuition is as follows. If the informed agents were to form a bank, they could try to communicate information about $v$ to the borrower. This information communication may be either truthful or not. With truthful communication, the borrower invests $\bar{K}$ whenever optimal. However, once the borrower learns $v$, it has no incentive to compensate the bank for its information acquisition cost. It can make a "take it or leave it" offer to the bank that merely yields the bank a zero expected profit on the loan itself. Since $M$ is a sunk cost, the bank will find it in its own interest to accept the offer, thereby violating the ex ante participation constraints of informed agents. If communication is not truthful, then this problem is exacerbated, as the borrower remains uninformed about $v$ and thus chooses $K=0 .{ }^{10}$ On the other hand, if the informed agents compete as traders in the financial market, each can recover his information acquisition cost because the presence of liquidity traders makes prices noisy and sustains the ex post trading profits of those with privileged information.

But if the monitoring agents decide to trade in the financial market as well, they face a coordination failure. Since a certain mass of them must choose to monitor in order to be effective, each monitoring agent must rely on sufficiently many others to monitor as well. But since each agent is arbitrarily small, this arrangement is beset with a free-rider problem in that there is at least one Nash equilibrium in which no agent monitors in the financial market. An effective way to resolve this problem is to form a coalition of monitoring agents whose measure is precisely $\Lambda^{*}$. These monitoring agents can observe each other's actions costlessly and thus implement a coordinated monitoring strategy. This endogenously gives rise to a financial intermediary, as in Ramakrishnan and Thakor (1984). Each monitoring agent contributes his $\$ 1$ endowment for lending and an additional $\$ M$ for monitoring, so that these agents supply $\$ \Lambda^{*}$ of loanable funds and $\$ \Lambda^{*} M$ of monitoring resources; the remaining $\$ 1-\Lambda^{*}$ of loanable funds is collected from nonmonitoring discretionary depositors. ${ }^{11}$ The en-

\footnotetext{
${ }^{10}$ We find the case involving no truthful revelation of information to be the most realistic. It also rules out trivial alternative resolutions, for example, a borrower hiring an agent to produce information about $v$.

${ }^{11}$ Our modeling of the impact of agents in the information production and monitoring cases is symmetric in the sense that, in both cases, individual agents are viewed as (almost) atomistic in their impact. In the financial market equilibrium, it will turn out that there must be sufficiently
} 
dogenously emerging role of banks as monitors is reminiscent of the role of banks in Diamond (1984). However, whereas the banks in Diamond's model monitor ex post cash flows, the banks here monitor ex ante project choices.

The role of banks that we have characterized is consistent with the key qualitative asset transformation functions served by real-world depository institutions [see Bhattacharya and Thakor (1993)]. For example, depository institutions that make loans and monitor borrowers to influence credit risk look very much like the banks in our model. Specifically, our banks are mutuals owned by their depositors. The nonmonitoring depositors are "pure" financiers, whereas the monitoring depositors are both depositors and loan officers since they monitor borrowers. This is akin to real-world mutual depository institutions in which there are depositors who are not involved in the management of the mutual and managers who hold ownership stakes by virtue of their deposits.

\section{The Analysis and Equilibrium Definition}

\subsection{Determination of interest rates}

3.1.1 Bank lending. The bank monitors the borrower's choice of project but does not learn $v$. Thus, there is no information feedback about $v$ from the bank to the borrower, and by Equation (1) the borrower cannot be induced to invest $K=\bar{K}$. The competitive bank's loan interest rate is set to yield an expected profit of zero. Thus, the loan interest factor (one plus the interest rate) $r_{B}$ solves $\eta r_{B}=$ $1+\Lambda^{*} M$, or

$$
r_{B}=\frac{1+\Lambda^{*} M}{\eta} .
$$

Note that in deriving Equation (3) we have allowed the bank to recoup its monitoring cost. The reason is as follows. The bank's monitoring cost ( $M$ times the measure of monitoring agents) is incurred in the postlending stage, and at this stage it is in the bank's best interest to monitor. This is because the lack of bank monitoring means that the borrower will invest in the good project only with probability $\theta$; recall that the realization of whether the borrower has access to a bad project is privately observed by the borrower that precludes realization-contingent monitoring. The bank's expected profit on the

many informed traders for the security price to be influenced by their trades. And in the banking equilibrium, there must be sufficiently many monitoring agents to deter asset-substitution moral hazard. 
loan (if it does not monitor) is

$$
\theta \eta \frac{\left[1+\Lambda^{*} M\right]}{\eta}-1=\theta\left[1+\Lambda^{*} M\right]-1<0
$$

by Equation (2). Thus, when the competitive bank quotes a price prior to making the loan, its quoted price must include the monitoring cost $\Lambda^{*} M$ in order to satisfy the bank's participation constraint.

3.1.2 Financial market funding. As will become apparent later, informed traders submit orders for the security only when their signal reveals that $v=1$. The market maker observes the total order flow and has to decide whether total demand is such that the borrower will be induced to invest $\bar{K}$ in improving the project. From Equation (1), we know that this investment is socially efficient (first best) only when the probability that $v=1$ is sufficiently high, that is, when $\operatorname{Pr}(v=1 \mid D) \alpha>\bar{K}$, where $\operatorname{Pr}(\nu=1 \mid D)$ is the posterior probability that the borrower (or the market maker) assigns to the event $v=1 .^{12}$ Of course, a borrower will be induced to invest only if

$$
\operatorname{Pr}(\nu=1 \mid D) \eta \alpha>\bar{K} .
$$

Note that Equation (4) is more stringent than the social efficiency condition, because a borrower with a good project benefits from investing $\bar{K}$ only if the project succeeds, even though the improvement, $\alpha$, occurs in both the successful and unsuccessful states if $v=1$ is realized. The reason is that $\alpha<1$, so that all of it accrues to the lender (investors in the bond) if the unsuccessful state is realized. This distorts the borrower's decision further away from the first best (attainable with self-financing). This is the usual underinvestment moral hazard or debt overhang problem.

We now define $D_{\min }$ as the minimum total demand to induce the borrower to invest $\bar{K}$ in improving the project. That is (see Equation (4)),

$$
\operatorname{Pr}\left(v=1 D_{\min }\right) \eta \alpha=\bar{K} .
$$

Since $\operatorname{Pr}(v=1 \mid D)$ is monotonically increasing in $D$ (we will verify this), we have

$$
\operatorname{Pr}(\nu=1 \mid D) \eta \alpha>\bar{K} \quad \text { for } \quad D>D_{\min } .
$$

Therefore, for $D>D_{\min }$, the borrower invests in project improvement. The best decision rule, given the observability problem about $v$ (second best), would be to choose the cutoff $D^{*}$ such that $\operatorname{Pr}(v=$

${ }^{12}$ Total demand will convey no information about $v$ if $\Omega=0$ in equilibrium. 


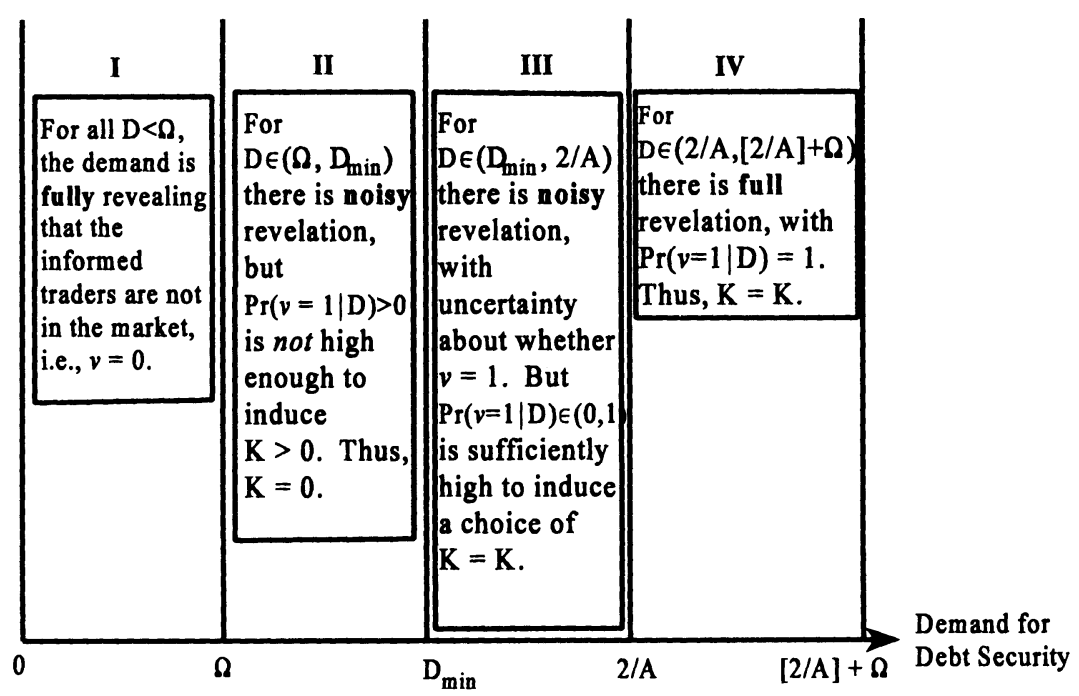

Figure 4

A schematic of financial market realizations of security demand and inferences

$\left.1 \mid D^{*}\right) \alpha=\bar{K}$. The decision rule of investing only when $D>D_{\min }$ is therefore more distortionary. We will later verify that the $D_{\min }$ defined in Equation (5) exists.

In Figure 4 we describe the inference process underlying the information feedback that occurs in the financial market. With the help of this figure, we can derive the interest rates that are set in the financial market. Henceforth, we consider the limiting case in which an individual trader's measure $\epsilon=0$, that is, each trader is atomistic. Where appropriate, we will point out what happens if $\epsilon$ is small but positive. Let $r(D)$ be the equilibrium interest factor as a function of the realized demand $D$. First, for $D \in\left[0, D_{\min }\right]$, we have $K=0$. Thus, $r(D)=r_{\max }$, where $\theta \eta r_{\max }+[1-\theta] \times 0=1$. Thus,

$$
r_{\max }=\frac{1}{\theta \eta}
$$

Note that in deriving Equation (6), we have used the result that the financial market does not monitor borrowers. Next, for $D \in\left(D_{\min }, 2 / A\right)$, we have $K=\bar{K}$ and $\operatorname{Pr}(\nu=1 \mid D)>\bar{K} / \eta \alpha$. Thus (see Equation (4)), $r(D)=\hat{r}(D)$, where $\theta\{\operatorname{Pr}(\nu=1 \mid D)[\eta \hat{r}(D)+[1-\eta] \alpha]+[1-\operatorname{Pr}(\nu=$ $1 \mid D)][\eta \hat{r}(D)]\}=1$, or

$$
\hat{r}(D)=\frac{1-\theta \operatorname{Pr}(\nu=1 \mid D)[1-\eta] \alpha}{\theta \eta} .
$$


Finally, for $D \in\left[\frac{2}{A}, \frac{2}{A}+\Omega\right]$, we have $K=\hat{K}$ and $\operatorname{Pr}(v=1 \mid D)=1$. Thus, $r(D)=r_{\min }$, where

$$
\begin{gathered}
\theta\left\{\eta r_{\min }+[1-\eta] \alpha\right\}=1, \quad \text { or } \\
r_{\min }=\frac{1-\theta[1-\eta] \alpha}{\theta \eta} .
\end{gathered}
$$

\subsection{Definition of equilibrium in the financial market}

A noisy rational expectations Nash equilibrium is:

(i) a measure of informed traders, $\Omega^{*}$, such that the expected profit of each informed trader is zero (and the first derivative of this expected profit with respect to $\Omega$ is negative at $\Omega^{*}$ ) when each informed trader takes as given the equilibrium strategies of the other potentially informed traders and the liquidity traders, and all other participants, including banks and borrowing firms, but assumes that the impact of his own trade on the price is negligible;

(ii) an aggregate security demand from informed and uninformed liquidity traders equal to

$$
D^{*}(v, \ell)=\Omega^{*} d_{I}(v)+\ell
$$

(iii) a market-clearing interest factor $r(D)$, which is determined by the market maker in such a way that the supply and demand for the debt security are equated, and the expected net gain to the a priori uninformed market maker is zero, conditional on the information contained in the order flow; and

(iv) an investment choice $K$ by each borrowing firm that is conditional on the information contained in the demand for its debt security and is made to maximize the firm's net expected profit, taking as given the equilibrium strategies of all other participants.

It is intuitive that the equilibrium expected profit of each informed trader is zero [see also Boot and Thakor (1993a)]. This would be sufficient if we could guarantee that the expected profit of an informed trader was monotonically decreasing in $\Omega$. However, this is not necessarily true here because an increase in $\Omega$ exerts two opposing influences on the expected profit of the informed. On the one hand, we have the usual effect that an increase in $\Omega$ makes the equilibrium price reflect more of the information possessed by the informed and hence reduces their expected profit. But on the other hand, the increased price informativeness also makes it more likely that the borrower will choose $K=\bar{K}$ when the informed are in the market. This increases the expected profit of the informed as $\Omega$ increases. Hence, for an $\Omega$ to qualify as the equilibrium measure of informed, it must also be 
true that, taking both these effects into account, a small increase in $\Omega$ reduces the expected profit of an informed trader below zero.

Note that our modeling of markets and institutions is symmetric from the standpoint of competitive structure. Each bank's expected profit is zero in equilibrium, and each informed trader earns a zero expected profit in equilibrium, net of the information acquisition cost.

\section{Further Analysis}

\subsection{Derivation of $D_{\min }$}

We wish to ensure that $D_{\min }$ is in the interior of its feasible range. By Bayes's rule we know that

$$
\begin{aligned}
\operatorname{Pr}(\nu=1 \mid D) & =\frac{f(D-\Omega) \gamma}{f(D-\Omega) \gamma+f(D)[1-\gamma]} \\
& =\frac{\gamma[A-B\{D-\Omega\}]}{\gamma[A-B\{D-\Omega\}]+[1-\gamma][A-B D]},
\end{aligned}
$$

where $B \equiv A^{2} / 2$. Note that $\partial \operatorname{Pr}(v=1 \mid D) / \partial D>0$. We now substitute the above expression in Equation (4). Writing $S \equiv \bar{K} / \eta \alpha$ yields (note that $S>\gamma$ )

$$
D_{\min }^{*} \equiv D_{\min }^{*}(\Omega)=\frac{A}{B}-\frac{[1-S] \gamma \Omega}{[S-\gamma]} .
$$

The solution for $D_{\mathrm{min}}^{*}$ stated in Equation (10) exists if and only if $D_{\min } \geq \Omega$. Otherwise $D_{\min }=\Omega$, and interval II in Figure 4 vanishes. Thus, the desired cutoff demand level, $D_{\min }$, is

$$
D_{\min }=\Omega \vee D_{\min }^{*},
$$

where $\vee$ is the max operator. Thus, the minimum total demand for the security that will induce the borrower to invest is $D_{\min }^{*}$ (the value of demand such that the expected payoff enhancement to the borrower exactly equals $\bar{K}$, the investment in payoff enhancement) unless $D_{\min }^{*}$ is less than $\Omega$, the measure of informed agents. In this case, the minimum total demand to induce an investment of $\bar{K}$ must be $\Omega$, since any $D<\Omega$ leads to $\operatorname{Pr}(v=1 \mid D)=0$.

\subsection{Determination of equilibrium measure of informed traders}

If we assume that $D_{\min }=D_{\min }^{*}$ (see Equation (11)), then the expected profits of the informed, for a given $\Omega$, can be expressed as:

$$
V=-M+\theta \eta \gamma \int_{D_{\min }-\Omega}^{[2 / A]-\Omega}\left\{\hat{r}(\Omega+\ell)-r_{\min }\right\} f(\ell) d \ell,
$$


where we have $D=\Omega+\ell$ in the range over which the integration in Equation (12) is performed. The limits of the integration arise from the fact that it is only when $D$ goes from $D_{\min }$ to $2 / A$ that the borrower chooses the value-enhancing investment $\bar{K}$ and revelation is noisy (so that the informed can profit). In this range, the informed are in the market (i.e., they know that $v=1$ ) and the total demand $D$ is sufficiently revealing so that $r_{\min }$ is the break-even interest factor on the firm's bond. What the firm is being charged is $\hat{r}(\Omega+\ell)$, which is the equilibrium interest factor determined in the financial market. The informed profit because $\hat{r}(\Omega+\ell)>r_{\text {min }}$. We now have the following result.

Proposition 2. The lowest value of $\Omega$ such that the expected profit of each informed trader is zero is given by

$$
\Omega_{1}=\sqrt{M / X},
$$

where $X \equiv \theta \gamma \alpha[1-\eta][1-\gamma]\left\{A^{2} \gamma \Gamma_{1}\left[1-\gamma+\gamma \Gamma_{1}\right]+\frac{A^{2} \gamma(1-\gamma)}{2} \ln \left(\Gamma_{2}\right)\right\}$

$$
\begin{gathered}
\Gamma_{1} \equiv \frac{[1-\{\bar{K} / \eta \alpha\}]}{[\{\bar{K} / \eta \alpha\}-\gamma]} \\
\Gamma_{2} \equiv \frac{[\{K / \eta \alpha\}-\gamma]}{[1-\gamma]} .
\end{gathered}
$$

Moreover, $\partial V / \partial \Omega>0$ at $\Omega=\Omega_{1}$.

According to the definition of the equilibrium, $\Omega^{*}$ has to be such that each informed trader earns an expected profit of zero. $\Omega_{1}$ satisfies this requirement. However, because $\partial V / \partial \Omega_{1}>0$, it must be the case that $\Omega_{1}$ is not the equilibrium measure of informed traders. At $\Omega=\Omega_{1}$, the increased informativeness of prices due to the presence of more informed traders increases the expected profit of each informed trader. For an equilibrium to exist, the function $V$ must slope down at some point and become zero again, as shown in Figure 5. That is, we have multiple solutions in $\Omega$ to the equation $V(\Omega)=0$, and $\Omega^{*}$ is the larger of the two $\Omega$ s satisfying this equation. This situation arises here because, unlike the usual setting, informed traders here both compete with and complement each other.

If $\epsilon>0$, then it is transparent that the larger of the two $\Omega$ s satisfying $V(\Omega)=0$ is the unique equilibrium, assuming that $\Omega>0 .{ }^{13}$ This is because at $\Omega=\Omega_{1}$, an additional individual trader can make a positive

${ }^{13}$ If the equilibrium $\Omega>0$, then it must be at least as great as $\Omega_{1}$ because $V(\Omega)<0 \forall \Omega<\Omega_{1}$. Note that $\Omega=0$ is always a candidate for equilibrium; it does not pay any agent of small measure $\left(\epsilon<\Omega_{1}\right)$ to become informed if $\Omega=0$. 


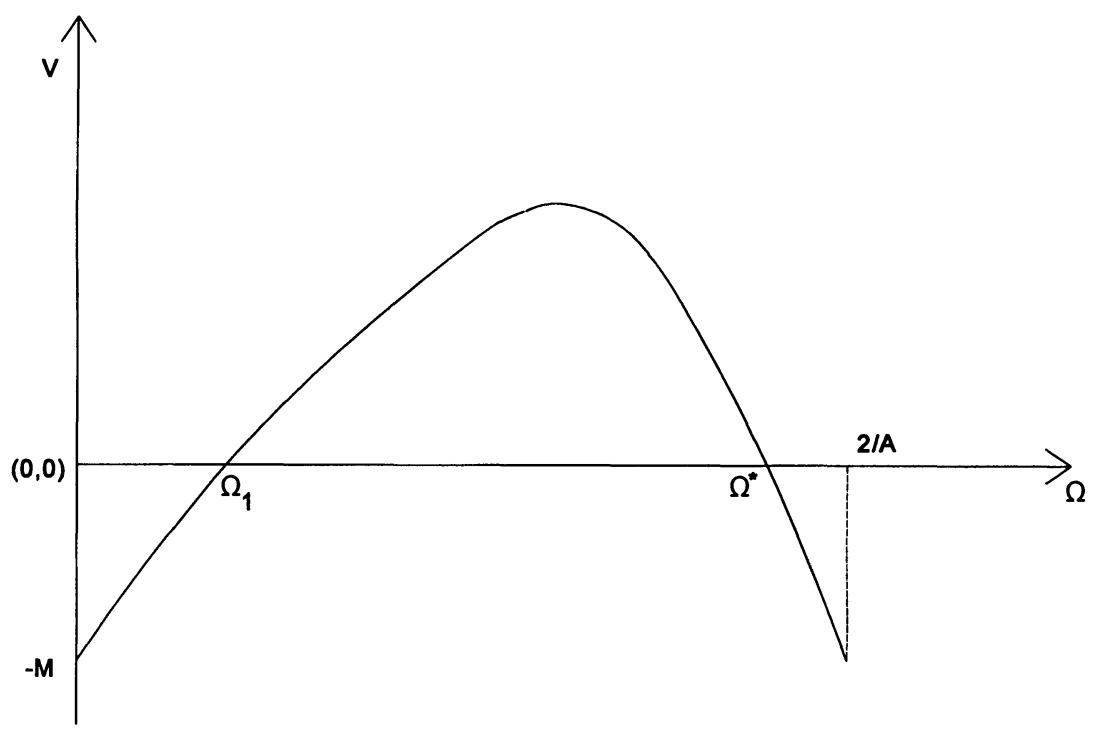

Figure 5

A graph of the expected profit of an informed trader as a function of the measure of informed traders

expected profit from becoming informed since $\partial V(\Omega) /\left.\partial \Omega\right|_{\Omega=\Omega_{I}}>0$, that is, $V\left(\Omega_{1}+\epsilon\right)>0$ for $\epsilon>0$. Thus, $\Omega_{1}$ cannot be an equilibrium with traders of arbitrarily small but positive measure. It is only at the limit itself, when $\epsilon=0$, that we have multiple equilibria-both values of $\Omega$ for which $V(\Omega)=0$ are possible equilibria under a somewhat less restrictive definition of equilibrium. ${ }^{14}$ The reason why $\Omega_{1}$ is an equilibrium in this case is that no additional trader would individually decide to enter the market when $\Omega=\Omega_{1}$ since his zero measure fails to increase $\Omega$ and this keeps $V$ at zero. Because we view this economy as only the limiting case of an economy with small but positive measure agents, we will henceforth focus only on the larger of the two $\Omega$ s for which $V(\Omega)=0$.

We have assumed thus far that $D_{\min }=D_{\min }^{*}$, and with this we obtain a solution $\Omega_{1}$ to $V(\Omega)=0$ such that $\partial V / \partial \Omega>0$ at $\Omega=\Omega_{1}$. As will be shown, increasing $\Omega$ above $\Omega_{1}$ to $\Omega^{*}$ will switch $D_{\min }$ in Equation (11) to $D_{\min }=\Omega^{*}$. Like Equation (12), the expected profit to the informed

\footnotetext{
${ }^{14}$ Strictly speaking, according to our definition of equilibrium, $\Omega_{1}$, is not an equilbrium. But our discussion here serves to clarify the reason why in our equilibrium definition we imposed the restriction $\partial V / \partial \Omega<0$ on the equilibrium $\Omega$. We thank Neil Wallace for discussing this with us.
} 
can now be written as ${ }^{15}$

$$
V=-M+\theta \eta \gamma \int_{0}^{[2 / A]-\Omega}\left\{\hat{r}(\Omega+\ell)-r_{\min }\right\} f(\ell) d \ell .
$$

We now have our next result.

Proposition 3. There is a set of exogenousparametervalues for which the equilibrium measure of informed traders, $\Omega^{*}$, is the solution to

$$
\begin{aligned}
V\left(\Omega^{*}\right) & =-M+\theta \gamma \alpha[1-\eta][1-\gamma]\left\{1-A \gamma \Omega^{*}+\left[\Omega^{*}+\left(\Omega^{*}\right)^{2} J\left(\Omega^{*}\right)\right]\right\} \\
& =0
\end{aligned}
$$

where

$$
J\left(\Omega^{*}\right) \equiv \frac{A^{2} \gamma}{2}-\frac{A^{2}}{4}+\frac{A^{2} \gamma[1-\gamma]}{2}\left\{\ln \left(\frac{A \Omega^{*} \gamma / 2}{1-\left[A \Omega^{*}\{1-\gamma\} / 2\right]}\right)\right\} .
$$

Moreover, $D_{\min }^{*}(\Omega)<\Omega^{*}$ at $\Omega=\Omega^{*}$, so that $D_{\min }=\Omega^{*}$ (see Equation (11)).

We can now examine some interesting properties of the financial market equilibrium.

Proposition 4. The equilibrium measure of informed traders is positive only if, for a given $M, \theta$ is sufficiently bigh, or, for a given $\theta, M$ is sufficiently low.

This proposition is intuitive. When the moral hazard problem is severe (the observable $\theta$ is low), a potentially informed trader anticipates that even her superior information about $v$ does not reduce the high probability that she will invest in a firm that chooses a bad project and imposes a loss on her. This reduces her incentive to become informed at a cost. If $\theta$ is sufficiently low, no potentially informed trader may choose to acquire costly information. Similarly, for a given $\theta$, an increase in $M$ reduces the expected profit of an informed trader, and a sufficiently high $M$ will cause a breakdown of the market for information. This also highlights another interesting result, which is stated below.

${ }^{15}$ In Figure 5, Equation (12) and Equation (14) we have implicitly assumed that $\Omega<2 / A$. It is easy to see why this holds. Note that if $\Omega \geq 2 / A$, where $2 / A$ is the maximum realization of liquidity demand, then there are only two possibilities: (i) $D<2 / A$, in which case the market maker infers that the probability is 1 that the informed traders are not in the market, and (ii) $D \geq 2 / A$, in which case the market maker infers that the probability is 1 that the informed traders are in the market. In both cases, prices are fully revealing and the informed can earn no profit on their information Hence, $\Omega \geq 2 / A$ cannot be the equilibrium measure of informed traders. 
Proposition 5. The expected profit of an informed trader is always maximized at some $\Omega>0$.

In Boot and Thakor (1993a), for example, the expected profit of an informed trader is always maximized at $\Omega=0$, that is, when there are no other informed traders in the market. This is never true here since a borrower with a good project always eschews its investment in project improvement if it knows there is nothing to be learned from market prices. Given this, it does not pay for any investor to become informed. Thus, as Figure 5 shows, an informed trader earns a higher expected profit when there is a positive measure of informed traders in the market and the borrower views the market price as an information communicator. This means that if the $V$ function were to have a maximum value that was negative, ${ }^{16}$ then no one will choose to become informed in equilibrium (i.e., the equilibrium $\Omega=0$ ). Another way of saying this is that an investor will become informed only if she believes there will be a sufficiently large number of others who will also choose to become informed.

\subsection{The borrower's choice of financing source}

The borrower's expected utility is the expected return net of its borrowing cost. If a borrower chooses the financial market, its borrowing cost depends on the anticipated informativeness of the market price of its debt. We have shown that the equilibrium measure of informed traders is $\Omega^{*}$ and that $D_{\min }=\Omega^{*}$ is the appropriate aggregate demand cutoff [see Equation (11) and Proposition 3]. Therefore, whenever the informed discover $v=1$ and are in the market, the borrower will find that $D \geq D_{\min }$, and hence will choose $K=\bar{K}$. But it is possible that the borrower will choose $\bar{K}$ even when the informed have discovered $v=0$ and do not bid for the firm's debt since $\ell \geq D_{\min }$ is possible.

The expected return of the borrower from financial market borrowing is given by

$$
E\left(R^{F}\right)=\theta\left\{\gamma E\left(R^{F} \mid v=1\right)+[1-\gamma] E\left(R^{F} \mid v=0\right)\right\}+[1-\theta] N,
$$

where $E\left(R^{F}\right)$ is the unconditional expected return and $E\left(R^{F} \mid v\right)$ is the expected return conditional on the realization of $\nu$. To understand Equation (16), recall that the borrower invests in the good project with financial market funding only if it is locked into that project (this happens with probability $\theta$ ), and invests in the bad project whenever

\footnotetext{
${ }^{16}$ At $\Omega=0$, it is always the case that $V<0$.
} 
it has a choice (this happens with probability $1-\theta$ ). Note that

$$
\begin{aligned}
E\left(R^{F} \mid \nu=1\right)= & \int_{0}^{[2 / A]-\Omega^{*}}\left\{\eta\left[Y+\alpha-\hat{r}^{*}\left(D=\ell+\Omega^{*}\right)\right]-\bar{K}\right\} f(\ell) d \ell \\
& +\int_{[2 / A]-\Omega^{*}}^{2 / A}\left\{\eta\left[Y+\alpha-r_{\min }\right]-\bar{K}\right\} f(\ell) d \ell
\end{aligned}
$$

and

$$
\begin{aligned}
E\left(R^{F} \mid v=0\right)= & \int_{0}^{\Omega^{*}}\left\{\eta\left[Y-r_{\max }\right] f(\ell) d \ell\right. \\
& +\int_{\Omega^{*}}^{2 / A}\left\{\eta\left[Y-\hat{r}^{*}(D=\ell)\right]-\bar{K}\right\} f(\ell) d \ell,
\end{aligned}
$$

where

$$
\hat{r}^{*}(\ell)=\frac{1-\theta \operatorname{Pr}(\nu=1 \mid D)[1-\eta] \alpha}{\theta \eta}
$$

and

$$
\operatorname{Pr}(\nu=1 \mid D)=\frac{\gamma\left\{A-B\left[D-\Omega^{*}\right]\right\}}{\gamma\left\{A-B\left[D-\Omega^{*}\right]\right\}+[1-\gamma]\{A-B D\}} .
$$

Next, we turn to bank financing. The cost of bank borrowing is given by Equation (3). Thus, the expected return for the borrower is given by

$$
E\left(R^{B}\right)=\eta Y-E\left(r_{B}\right)=\eta Y-1-\Lambda^{*} M,
$$

since interbank competition ensures that $E\left(r_{B}\right)=1+\Lambda^{*} M$. The borrower's choice of financing source is determined by comparing $E\left(R^{F}\right)$ and $E\left(R^{B}\right)$. This gives us the following result.

Proposition 6. There exists a cutoff value of $\theta$, say $\hat{\theta}$ (assumed to be in the interior of $[\underline{\theta}, \bar{\theta}])$, such that there is a Nash equilibrium in which borrowers with observable $\theta \leq \hat{\theta}$ choose bank financing and borrowers with observable $\theta>\hat{\theta}$ choose financial market financing. Moreover, $\hat{\theta}$ is increasing in $M$.

Figure 6 shows how the net return for a borrower changes as a function of its observable quality $\theta$. It is intuitive that borrowers with lower observable quality prefer bank financing. Banks specialize in attenuating asset-substitution moral hazard, so the borrower does not suffer a loss in utility with bank financing as this problem worsens. That is, the borrower's expected return with bank financing is invariant to $\theta$. On the other hand, the benefit of financial market financing to the borrower is increasing in $\theta$. The reasons are twofold. First, the 


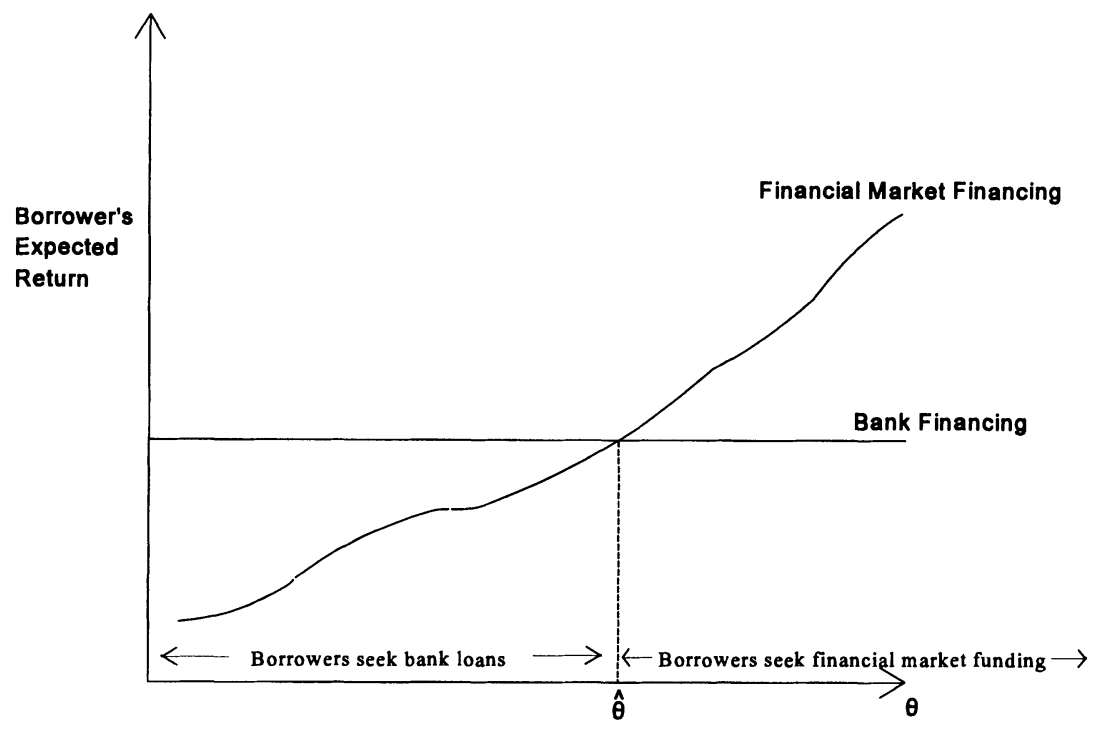

Figure 6

A graph of the expected returns of a borrower as a function of the borrower's observable quality

Borrowers with observable qualities below threshold $\hat{\theta}$ choose bank financing and those with observable qualities above threshold $\hat{\theta}$ choose financial market financing.

expected profit of an informed trader is increasing in $\theta$ [see Equation (14)], so that the higher the $\theta$, the larger is the equilibrium measure of the set of informed traders for the debt security sold by the borrower. This means that the equilibrium interest factor reflects more of the information possessed by the informed traders and is consequently lower on average. Second, the "moral hazard premium" paid by borrowers in the financial market is decreasing in $\theta$.

Numerical simulations of the model (details available upon request) illustrate that $\hat{\theta}$ increases as $M$ increases. The intuition is clear. An increase in $M$ reduces the expected profit of an informed trader ceteris paribus. This causes a reduction in $\Omega^{*}$, leading to a decline in the value of financial market financing for the borrower. If the increase in $M$ refers only to an increase in the information acquisition cost, but not in the monitoring cost, then it is transparent that bank financing will become more attractive, leading to a larger set of observable quality levels choosing bank financing. What our numerical analysis shows is that bank financing becomes more attractive with an increase in $M$ even when this increase applies equally to the costs of information acquisition and monitoring.

We next consider the implication of permitting only noisy moni- 
toring by the bank. Suppose that, conditional on being in the state in which the borrower has a choice of project, the bank can enforce the choice of the good project only with probability $\xi \in(0,1)$. We then have the following result.

Proposition 7. If the bank can prevent the choice of the bad project only with probability $\xi \in(0,1)$, there exists a $\theta^{0}$ (assumed to be in the interior of $[\underline{\theta}, \bar{\theta}]$ ) such that there is a Nash equilibrium in which borrowers with observable $\theta \leq \theta^{0}$ prefer bank financing and borrowers with observable $\theta>\theta^{0}$ prefer financial market financing. Moreover, the value of bank financing to the borrower is increasing in $\theta$, and $\theta^{0}<\hat{\theta}$.

Thus, we see that while noise in the monitoring technology reduces the value of bank financing to the borrower ceteris paribus $\left(\theta^{0}<\hat{\theta}\right)$, we still encounter the earlier result that borrowers with relatively high $\theta$ s access the financial market and borrowers with relatively low $\theta$ s approach banks. ${ }^{17}$ One noteworthy difference that noisy monitoring makes is that it causes the borrower's net expected payoff with bank financing to be increasing in $\theta$, rather than being invariant to $\theta$. The intuition is that the higher the $\theta$, the lower is the probability that the noise in its monitoring technology will obstruct the bank's ability to deter selection of the bad project, and hence the lower is the bank's loan interest factor. There is a fairly large literature on the borrower's choice of financing source that we do not discuss here. [For example, Diamond (1991), Berlin and Mester (1992), Hirshleifer and Suh (1992), Rajan (1992), Wilson (1994), and Thakor and Wilson (1995). See Bhattacharya and Thakor (1993) for a review.] Unlike that literature, we endogenize banks and the financial market. Moreover, our result here is novel in that it links the borrower's choice to its observable quality in a moral hazard setting and predicates this link on the cost of information acquisition in the financial market.

\section{Model Robustness and Extensions}

In this section we indicate how our model could be generalized along some important dimensions: the possibility of eliminating noise traders, the use of equity rather than debt in the financial market, information aggregation involving traders with information, the simultaneous use of bank and financial market funding, and the impact of institutional sellers. Our conclusion is that the analysis can be extended in all of these directions without qualitatively altering its results.

17 Of course, the limit of $\xi \rightarrow 0$ involves the financial market dominating banks for all $\theta$. 


\subsection{Elimination of noise traders and introduction of equity}

The liquidity traders in our model are "noise" traders in the sense that they make expected losses from trading. Indeed, their losses enable the informed traders to earn the profits that justify their investment in information. While this is a standard assumption in market microstructure models, one may find the presence of noise traders in our analysis somewhat awkward. In particular, why wouldn't these traders invest exclusively in securities that are immune to adverse selection concerns? Why don't they deal with banks rather than the financial market?

Clearly, in any model in which agents potentially acquire private information at a cost, there must be sufficient noise in equilibrium prices to make it privately optimal for agents to become informed. However, it is unnecessary for the agents who provide the noise to sustain trading losses. We could assume instead that it is the issuing firm that loses through the systematic underpricing of its security. The liquidity traders could then break even. This would be in the spirit of Rock's (1986) IPO underpricing model. We will show shortly that this approach is consistent with our model.

Consider now the use of debt contracts in our analysis. From an information acquisition standpoint, equity is clearly better than debt to examine in a financial market context. We will also show that using equity instead of debt does not change our conclusions. To deal with this and the liquidity traders issue, we consider a simplified version of our model, an example.

Example 1: Data: Suppose $\theta=1, \gamma=0.4$, and $\eta=1$. Let $S$ represent the equity ownership share the firm must surrender to outside shareholders to raise the $\$ 1$ investment it needs. There are uninformed discretionary traders who can choose to become informed about $v$ at a cost of $M=0.24 \alpha[Y+0.5 \alpha]^{-1}$, and there are liquidity traders whose demand equals $\ell \in\{0,1 / 2\}$, with $\operatorname{Pr}(\ell=0)=0.6$, and $\operatorname{Pr}(\ell=1 / 2)=0.4$. The prior probability distribution of $v$ is $\operatorname{Pr}(v=1)=0.4$, and $\operatorname{Pr}(v=0)=0.6$. Assume that $\alpha>2 \bar{K}$ and $\gamma \alpha<\bar{K}$, and that $\bar{K}$ is an unobserved private investment by the firm.

Analysis: We conjecture that $\Omega=1 / 2$. Informed traders will submit a purchase order only when $v=1$. Note that $\alpha>2 \bar{K}$ ensure that the firm invests $\bar{K}$ whenever $D \geq 1 / 2$. Since the available supply of equity for outsiders to buy is $\$ 1$, there are only three relevant states:

(i) $v=1$ and $\ell=1 / 2$, so that the total demand from the liquidity traders and informed traders is $\$ 1$. In this case $\operatorname{Pr}(v=1 \mid D=$ 1) $=1$, and the uninformed discretionary traders buy 0 .

(ii) $v=1$ and $\ell=0$ or $v=0$ and $\ell=1 / 2$, so that the total demand 
Table 1

Outside investors' ownership fractions for different loan demand realizations

\begin{tabular}{llll} 
& \multicolumn{3}{c}{ Realized total demand } \\
\cline { 2 - 4 } Description & $D=\$ 1$ & $D=\$ 1 / 2$ & $D=\$ 0$ \\
\hline Inference of & $v=1$ and $\ell=1 / 2$ & $v=0$ and $\ell=1 / 2$ & $v=0$ and $\ell=0$ \\
market maker & & or & \\
& & $v=1$ and $\ell=0$ & \\
$S_{\text {Fairly Priced }}(D)$ & {$[Y+\alpha]^{-1}$} & {$[Y+0.5 \alpha]^{-1}$} & $Y^{-1}$ \\
$S_{\text {Underpricing }}(D)$ & {$[Y+1.25 \alpha]\{[Y+0.5 \alpha][Y+\alpha]\}^{-1}>$} & {$[Y+0.5 \alpha]^{-1}$} & $Y^{-1}$ \\
& {$[Y+\alpha]^{-1}$} & & \\
\hline
\end{tabular}

$D$ from liquidity traders and informed traders is $\$ 1 / 2$. The UDTs buy $\$ 1 / 2$ worth of equity. Using Bayes's rule, the posterior probability assessment that the firm has that the informed traders have observed $v=1$ can be determined as

$$
\begin{aligned}
\operatorname{Pr}(v= & 1 \mid D=1 / 2) \\
& =\frac{\operatorname{Pr}(D=1 / 2 \mid v=1) \operatorname{Pr}(v=1)}{\operatorname{Pr}(D=1 / 2 \mid v=1) \operatorname{Pr}(v=1)+\operatorname{Pr}(D=1 / 2 \mid v=0) \operatorname{Pr}(v=0)} \\
& =\frac{0.24}{0.48}=\frac{1}{2} .
\end{aligned}
$$

(iii) $v=0$ and $\ell=0$, so that the total demand $D$ from liquidity traders and informed traders equals $\$ 0$, and $\operatorname{Pr}(v=1 \mid D=0)=0$. The uninformed discretionary traders buy $\$ 1$ of equity.

Table 1 summarizes the ownership fractions outsiders obtain in the three different states. It can be verified that these ownership fractions are such that

(i) The uninformed discretionary traders earn zero expected profit;

(ii) The liquidity traders earn zero expected profit;

(iii) The informed traders earn positive expected profits on their trades, but zero expected profits when their information production costs $M$ are taken into account;

(iv) The firm prefers to underprice $D=1$.

(v) $\Omega=1 / 2$ in equilibrium.

A proof of this is available upon request. Thus, our analysis is robust with respect to using equity instead of debt and ensuring that liquidity traders break even on average.

\subsection{Information aggregation}

Although we have assumed in our analysis that all informed traders obtain the same information, it is clear that information aggregation is an important element of the intuition behind our story. Without aggregation of heterogeneous signals in the financial market, we must 
rely solely on the inability of banks to internalize any benefits from information acquisition in order to obtain the sharp dichotomy of functions across banks and the financial market that is described in Proposition 1. Moreover, one might wonder why entrepreneurs can't directly acquire information about $v$, a single piece of information. That is, in order to simplify, our analysis ignores an important advantage of financial markets, namely to aggregate payoff-relevant information when it is widely dispersed in the economy and difficult to purchase directly.

In what follows, we provide a simple extension of our model that illustrates how financial markets may aggregate diverse information and how the desirability for such aggregation can further diminish the role of banks as pure information sellers.

Example 2: Data: Suppose $\theta=1, \gamma=0.25$, and $\eta=1$. There are two distinct signals, $x \in\{0,1\}$ and $y \in\{0,1\}$, that are conditionally uncorrelated, that provide information about $v$. In particular,

$$
\begin{gathered}
\operatorname{Pr}(x=0)=\operatorname{Pr}(y=0)=0.5 ; \\
\operatorname{Pr}(v=1)=0.25, \operatorname{Pr}(v=1 \mid x=1)=\operatorname{Pr}(v=1 \mid y=1)=0.5 ; \\
\operatorname{Pr}(v=1 \mid x=1, y=1)=1 ; \text { and } \\
\operatorname{Pr}(v=1 \mid x=1, y=0)=\operatorname{Pr}(v=1 \mid x=0, y=1) \\
=\operatorname{Pr}(v=1 \mid x=0, y=0\}=0 .
\end{gathered}
$$

There are liquidity traders whose demand $\ell \in\{0,1 / 2\}$, with $\operatorname{Pr}(\ell=$ $0)=\operatorname{Pr}(\ell=1 / 2)=0.5$. Let $S$ represent the equity ownership share the firm must surrender to outside shareholders to raise the $\$ 1$ investment it needs. There are uninformed discretionary traders who can choose to become informed about either $x$ or $y$, but not both, at a cost $M=$ $0.0625 \alpha[Y+0.5 \alpha]^{-1}$.

Analysis: For simplicity, we will assume that the firm's equity is fairly priced and therefore the liquidity traders make losses on average. Let the measure of those who invest to learn $x$ be $\Omega_{x}$ and the measure of those who invest to learn $y$ be $\Omega_{y}$. We conjecture that $\Omega_{x}=\Omega_{y}=\frac{1}{4}$, and that each group of informed traders will submit a purchase order only when the signal for that group takes a value of 1 .

There are now five relevant states, each distinguished by a different realization of total demand from the liquidity traders, those who are informed about $x$ and those who are informed about $y$. Let $D$ represent the total demand from these three groups. As usual, the market maker cannot distinguish the individual components of total 
demand, the price of the equity is set at its expected value conditional on the information contained in $D$, and the uninformed discretionary traders purchase equity in the amount needed to clear the market. Thus, $D \in\left\{0, \frac{1}{4}, \frac{1}{2}, \frac{3}{4}, 1\right\}$. These five states arise as follows.

(i) $D=0$ : This arises only when $x=0, y=0$, and $\ell=0$. The market maker unambiguously infers $v=0$. The probability of this state is 0.125 .

(ii) $D=1 / 4$ : This arises if $\ell=0, x=0, y=1$ or $\ell=0, x=1, y=0$. The market maker unambiguously infers $v=0$. The probability of this state is 0.25 .

(iii) $D=1 / 2$ : This arises if $x=1, y=1, \ell=0$ or $x=0, y=0$, $\ell=1 / 2$. In this state, $v$ could be either 0 or 1 . The probability of this state is 0.25 .

(iv) $D=3 / 4$ : This arises if $x=1, y=0, \ell=1 / 2$ or $x=0, y=1$, $\ell=1 / 2$. The market maker unambiguously infers that $v=0$. The probability of this state is 0.25 .

(v) $D=1$ : This arises only if $x=1, y=1, \ell=1 / 2$. The market maker unambiguously infers $v=1$. The probability of this state is 0.125 .

In states (i), (ii), and (iv), $S(D)=1 / Y$. In state (iii), $S(D)=$ $[Y+0.5 \alpha]^{-1}$. In state $(\mathrm{v}), S(D)=[Y+\alpha]^{-1}$. It is now straightforward to verify that the expected profit of each group of informed traders, per unit measure of informed traders, is exactly equal to $0.0625 \alpha[Y+0.5 \alpha]^{-1}$, which is $M$. This verifies our conjecture that $\Omega_{x}=$ $\Omega_{y}=\frac{1}{4}$.

\subsection{Direct information elicitation mechanisms}

A natural question that arises in the context of our analysis is why it is not possible to directly elicit the private information possessed by informed traders rather than have it indirectly revealed (noisily) through the equilibrium market price. In particular, one could think of informed traders coalescing to form a bank and selling information directly to the firm.

While this seems reasonable, it is plagued by the potential lack of credibility of the information that is communicated. The problem exists at two levels: within the bank, and between the bank and the firm. Consider the more important intrabank problem first. When there are multiple agents engaged in information production, a free-rider problem arises with unobservable individual inputs in information production since each agent bears the fall cost of his input and only shares in the collective output. Ramakrishnan and Thakor (1984) show that this problem can completely vitiate any risk-sharing gains from coalescing; they therefore examine the benefit of intermediation (coalition 
formation) when individual agents can costlessly monitor each other's inputs.

Their model has $n$ agents in the intermediary, each producing information about a distinct firm, so that the free-rider problem arises not from information aggregation but from each agent's payoff being a prorata share of the pooled payoff that represents the intermediary's compensation. Without costless internal monitoring, the agents within the intermediary cannot overcome their own free-riding incentives.

Information aggregation exacerbates this problem. This can be seen most readily within the context of Example 2, as well as more generally. In the context of the example, suppose that the bank consists of two groups of informed agents, one group specializing in $x$ and the other in $y$. Each group provides $\$ 0.5$ to the bank to enable it to lend $\$ 1$ to the firm. For simplicity, assume that there are no intragroup incentive problems and that members of each group can function as a single entity; we make this assumption to focus on intergroup incentive problems. The bank is competitive and is paid a fee that compensates it for the information acquisition costs of the two groups. Let the measure of each group be 1, so that each group is paid $M$ for its information acquisition.

Consider now the marginal benefit of becoming informed for each group within the bank, assuming that the bank always truthfully reports the information it receives from the two groups to the firm and that it gives each group $M$ plus its prorata share of the output accruing to the bank under its equity contract with the firm. Now, if a particular group produces information, its expected profit (assuming that the other group will also produce information) is zero, since the bank is competitively compensated, and in turn it seeks to just satisfy each group's reservation constraint.

On the other hand, if a particular group decides to always report 0 without producing information, then its expected profit (regardless of what the other group does) is $M$, since the firm does not make the value-enhancing decision. Similarly, if the group (say the $x$ group) unconditionally reports a signal value of 1 , its expected profit (assuming that the other group produces information and truthfully reports) can be shown to be less than $M$, since now this group bears some of the cost associated with the firm making a value-enhancing decision when it should not.

Thus, each group's dominant strategy is to report 0 without producing information. In particular, it is not a Nash equilibrium for each group to invest in information acquisition, given the intrabank contracting technology of giving each group $M$ plus its prorata share of the output accruing to the bank under its equity contract with the firm. Although mechanisms may be found to restore incentive compatibility 
in information acquisition within the bank, these are unlikely to be costless.

One such costly mechanism would be for the firm to offer the bank a higher expected payoff when the output is $Y+\alpha$ than when it is $Y$; this would reduce each group's incentive to unconditionally report 0 . If the firm's net payoff enhancement is sufficiently large relative to $M$, then perhaps each group within the bank can be "bribed" to report truthfully. What is interesting is that the ability of such a mechanism to restore incentive compatibility is weakened as we increase the number of signals that are being aggregated. To see this, suppose there are three signals, $x, y$, and $z$ in Example 2, with $\operatorname{Pr}(v=1 \mid x=1, y=$ $1, z=0$ or 1$)=\operatorname{Pr}(v=1 \mid x=0$ or $1, y=1, z=1)=\operatorname{Pr}(v=1 \mid$ $x=1, y=0$ or $1, z=1)=1$ and $\operatorname{Pr}(v=1 \mid 0$ for any two or more of $x, y$, and $z)=0$. Now, incentive compatibility will be more difficult to achieve because the strategy of unconditionally reporting 0 has become less costly to each group, conditional on the other two groups producing information and reporting truthfully. More generally, the intuition is that as we increase the number of signals being aggregated, each group's signal becomes less pivotal in its impact on the group's share of the output. Thus, misreporting incentives are strengthened with greater aggregation.

The second problem we alluded to earlier was between the bank and the firm. Even apart from the groups within the bank free riding on each other's inputs, the bank's incentive to generate costly and reliable information and truthfully report it may be weak. Firms may attempt to deal with this by appealing to the revelation principle and designing incentive contracts that link the bank's fees to performance in a way that achieves incentive compatibility. For example, the firm could sell the bank a call option with its payoff on the exercise date dependent on the realization of $v$; the exercise of this option would reveal information about $v$. However, there are three difficulties with such mechanisms. First, the firm would need to ensure that the option is not resold by the bank, or else the vexing problem of dealing with the coalitional incentive compatibility constraints associated with traded contracts arises. ${ }^{18}$ Second, if there are multiple signals that the bank reports to the firm for aggregation, then applying the revelation principle becomes particularly complex as multiple nontraded options must be offered. Third, suppose one interprets "noise" as agents/banks that mistakenly think they can acquire information, that is, these intermediaries mistakenly buy and exercise options that are valuable if and only if information is acquired. In such a world, the

\footnotetext{
${ }^{18}$ See Jacklin (1987) for an analysis of this in the context of traded deposit claims.
} 
market solution-which requires only the knowledge of the probability distribution of noise-is superior to revelation schemes that require knowledge of the agent type, that is, whether the signal sender in the scheme can indeed acquire the relevant signal. This problem too is exacerbated as one increases the number of signals being aggregated.

Thus the very reason that financial markets have a role for aggregating heterogeneous information puts financial intermediaries at a disadvantage in performing the same task.

Is our theory then at odds with the existence of institutions that sell information? ${ }^{19}$ While it is true that bond rating agencies and investment advisory firms sell information about corporations, the credibility of such information sellers and consequently the demand for their services depends on their reputation in possessing the requisite information-processing skills and providing reliable information. To the extent that this reputational mechanism is not perfect, institutional information sales will at best substitute only partially for the direct acquisition of information about $v$ by an informed trader. Thus, the presence of institutional information sellers could diminish the marginal profit from becoming informed, but will not eliminate it entirely. In particular, the preceding analysis suggests that institutional information sellers are likely to be viable only when relatively few pieces of information must be aggregated to provide a relevant set of information, whereas market-based information dissemination is likely to predominate when numerous pieces of information must be aggregated.

\subsection{Simultaneous access to bank loans and financial market funding}

While in our formulation a firm either chooses bank financing or chooses to fund itself in the financial market, we could envision firms lying along a continuum with sole bank or financial market funding as the polar extremes. This generalized version would allow firms to optimally balance the benefits of bank monitoring and financial market information aggregation. Such "mixed" financing would be useful in a variety of contexts. For example, Diamond (1993) shows that a mix of private and public debt can improve investment efficiency.

If asset-substitution moral hazard is severe (low $\theta$ ), a firm is likely to choose considerable bank funding to induce sufficient monitoring. The relatively small amount of funding raised in the financial market would provide some information aggregation benefits, although

\footnotetext{
${ }^{19}$ Ramakrishnan and Thakor (1984), Millon and Thakor (1985), Allen (1990), Kane and Marks (1990), and Fishman and Hagerty (1995) are examples of articles that rationalize institutions that sell financial information.
} 
these would not be large because the measure of informed traders $(\Omega)$ would be rather small in response to the low funding level. A high- $\theta$ borrower is likely to borrow considerably more in the financial market since its low monitoring demand necessitates only a small amount of bank funding to mitigate asset-substitution moral hazard. Thus, this firm can better exploit the information aggregation benefits of financial markets.

This formulation generalizes our results but does not alter them qualitatively.

\section{Implications for Financial System Architecture}

Our discussion in this section, which focuses on just a subset of the issues in financial system architecture, is organized in four parts. First, we examine the likely starting point for a "free-market" financial system. That is, if an economy is making a transition from being centrally planned to being in a free-market mode, what is likely to be the initial configuration of its financial system? Second, we examine the potential impact of financial innovation on borrowers' financing source choices and on real investment decisions. Third, we examine the implications of large ("block") financial market traders who are nonatomistic. Finally, we discuss what the analysis suggests for overall financial system design.

\subsection{The starting point of a new financial system}

In a new financial system-one previously managed by a central planner-the historical absence of profit-motivated banks or financial market traders implies possibly severe informational frictions pertaining to potential borrowers. In particular, asset-substitution moral hazard is likely to be rampant. Consequently, borrowers will have lower observable qualities $(\theta \mathrm{s})$ on average. This enhances the value of bank financing for two reasons. First, borrowers face a large "moral hazard premium" in the financial market. Second, lower $\theta$ s reduce the value of the informed traders' information, thereby weakening information acquisition incentives. Moreover, the expected lack of sophistication of financial market traders in such an economy connotes a higher cost to them of acquiring relevant borrower-specific information (i.e., $M$ is higher). This leads to a lower $\Omega^{*}$ at the outset than at the later stages of development of a financial market. Both these effects-lower $\Omega^{*}$ and higher $M$-generate a relatively high $\hat{\theta}$. Consequently, bank financing dominates a financial system during its infancy.

As the financial system evolves, successful borrowers will develop credit reputations that will ameliorate moral hazard and improve the average $\theta$ of the borrower pool [Diamond (1991)]. More borrowers 
will migrate to the financial market and traders will become more familiar with firms, leading to a lower $M$ and a higher $\Omega^{*}$. Thus, even a financial system that begins as a bank-dominated system will evolve to a system in which banks lose market share to the financial market.

\subsection{Financial market sophistication}

Greater sophistication in a financial market is often manifested in lower friction in informational flows. There are many ways in which such lower friction is achieved. One is through security design innovations that stimulate greater informed trading and improve liquidity [Back (1993) and Boot and Thakor (1993a)]. ${ }^{20}$ Another is through improved information transmission mechanisms that permit investors to acquire information at a lower cost. An example is the emergence of information-gathering agencies (e.g., Dun and Bradstreet) that provide lower-cost access to information. We shall focus on this latter characterization of financial market sophistication and assume that it lowers the cost of learning about $\nu$. The effect of a lower information acquisition cost is to increase $\Omega^{*}$, ceteris paribus. And an increase in $\Omega^{*}$ reduces the borrower's expected cost of funding in the capital market. Nothing changes for bank financing as long as the monitoring cost remains unchanged. Hence, $\hat{\theta}$ decreases and increased financial sophistication of this type results in banks losing market share to the capital market. This is consistent with recent financial history-the greatest shift in corporate borrowing from banks to the capital market has occurred in the United States, which has also led the world in financial market sophistication and efficiency. For a formal analysis of these issues, see Boot and Thakor (1996, forthcoming).

\subsection{Large financial market traders}

We have assumed that each financial market trader is atomistic. But what if individual traders were allowed to amass "block" holdings of bonds? This would have two potentially important effects. First, if a trader who acquired information about $v$ were to be endowed with sufficient investible wealth to submit a demand with positive measure, then such a large demand would noiselessly reveal the trader's superior information to the market maker and lead to a perfectly revealing price. To avoid the Grossman and Stiglitz (1980) paradox, we could provide the informed trader an opportunity to break up her trade into many smaller units, each of which would mimic the trade of an atomistic trader. Alternatively, we could permit liquidity traders

\footnotetext{
${ }^{20}$ A somewhat more subtle way in which security design can resolve informational problems in a dynamic setting is through contractual discretion that stimulates reputation development [see Boot, et al. (1993)].
} 
to also submit block orders. Either case would change the financial market equilibrium, but is unlikely to alter our principal conclusions.

More interesting, however, is the second effect. If monitoring agents were nonatomistic, an individual monitoring agent could be of measure $\Lambda^{*}$, which would trivially resolve the free-rider problem associated with capital market monitoring. Our model predicts that such larger traders would diminish the importance of banks and decrease $\hat{\theta}$. This is roughly consistent with the stylized facts in the United States in that the emergence of institutional investors (like CALPERS and TIAA-CREF) as active players in monitoring firms has coincided with a decline in banks' lending to corporations.

\subsection{Tentative thoughts on financial system design}

Our analysis predicts that an optimal financial system will configure itself skewed toward bank financing if borrowers have relatively poor credit reputations (a higher moral hazard propensity) and toward capital market financing if borrowers have relatively good credit reputations, but can improve real decisions based on the information conveyed by market prices. Moreover, capital market financing is more valuable for those borrowers who attach a high value to information regarding $v$.

Do these observations have anything to say about how a financial system will evolve if left to its own machinations? Our analysis provides some indications. In particular, our earlier observations on emerging financial systems suggest that the welfare relevance of financial markets should grow through time as the financial system develops. However, financial market growth will come at the expense of commercial banks. This implies that some institutional resistance from existing banks should be expected as financial markets grow in prominence. But unless the actions of banks are coordinated-in contrast to our assumption that competitive banks do not coordinate-it is unlikely that financial market growth can be retarded. Thus, it is possible that a critical factor in the development of the financial market is the fragmentation of the banking industry, which in turn may depend on the number of banks in the industry.

\section{Conclusion}

We have rationalized the coexistence of banks and financial markets based on assumptions about primitives-endowments, types of agents, and informational constraints. Banks arise as coalitions of agents who coordinate their actions to resolve asset-substitution moral hazard. The financial market arises to permit noncolluding agents to compete, and this facilitates the transmission of valuable informa- 
tion about market conditions with a concomitant impact on firms' real decisions. We find that borrowers who pose relatively onerous asset-substitution moral hazards prefer bank financing, and borrowers who pose less serious moral hazards go directly to the capital market. Moreover, increased financial market sophistication diminishes banks' market share.

The predictions of our theory match up with cross-sectional differences across industries. For example, our theory predicts that firms in industries with substantial state verification use financial markets, while firms in industries that require a lot of monitoring use banks. An example of this is the choice of venture capital versus financial market funding. Borrowers who have few tangible assets to offer as collateral pose particularly onerous moral hazards [see, e.g., Boot, Thakor and Udell (1991)] and require a lot of monitoring. We do find that such borrowers tend to seek financing from venture capitalists who specialize in monitoring. On the other hand, firms that rely on more complex technologies have more to gain from the feedback role of market prices and should prefer financial market funding. The evidence on cross-sectional financing patterns in the United States (e.g., the recent explosion of biotech and computer technology firms' IPOs) seems consistent with this. Allen (1993) comprehensively discusses the consistency of this aspect of our model with the cross-sectional and intertemporal evidence on global financing patterns. For example, Allen points out that stock market-based financial systems have been associated with 19th-century U.K., which was the first country to go through the Industrial Revolution, when managerial decision making ostensibly increased in complexity. Similarly, Mayer (1988) points out that between 1970 and 1985, companies in France, Germany, Japan, and the U.K. relied primarily on retained earnings and bank loans to finance investment, in contrast to U.S. firms that raised significant amounts in the bond markets. Allen (1993) suggests a possible explanation for this that is consistent with our model. He provides evidence that significantly more firms are covered by financial analysts in the United States than in these other countries, so that stock prices in U.S. financial markets are likely to reflect much more information of relevance to managers.

Recently, Carey (1995) provided empirical evidence that is supportive of our analysis. He found that informational asymmetries are not an important factor in bank loan contracting with large borrowers, but moral hazard is. He concludes from his evidence that bank loans are special primarily because of their moral hazard attenuation implications.

Our article has scratched only the surface of financial system design. There are other significant unresolved issues. Foremost is understand- 
ing how regulatory policies, aimed principally at banking scope, affect the financial system, particularly when one considers not only incentive problems between banks on the one hand and depositors and regulators on the other, but also between regulators and taxpayers [see Boot and Thakor (1993b) and Kane (1989, 1990)]. Such an exercise may point to potentially interesting multiperiod extensions of the analysis, creating a role for reputational rents and their interaction with regulation.

\section{Appendix}

Proof of Lemma 1. Suppose, counterfactually, that traders whose combined measure integrates to 1 , including a strictly positive measure of traders each having invested $M$ to learn about $v$, coalesce to form a bank that can lend $\$ 1$ to the same borrower. Suppose first that information communication is truthful. Then, once the borrower learns $v$, it will find it optimal to offer to pay the bank $\left\{\theta^{-1}-[1-\eta] \alpha\right\}\{\eta\}^{-1}+t$ if $v=1$ and $[1 / \eta \theta]+t$ if $v=0$, where $t$ is an arbitrarily small positive scalar approaching zero. This will be a "take it or leave it" offer. At these interest factors, each bank makes an expected profit of $t$ on the loan itself, thereby incurring a net expected loss because of its inability to recoup its information acquisition cost ( $M$ times the measure of informed traders in the bank). Of course, if information communication is not truthful, the borrower does not invest in $\bar{K}$. Thus, informed traders do not form a bank.

If these traders choose to trade independently in the capital market, however, they compete with each other. The presence of liquidity traders means that the equilibrium security price will not always fully reflect all of the informed traders' information. This noise in prices is sufficient to enable each informed trader to recoup $M$.

Proof of Lemma 2. Suppose, counterfactually, that the monitoring agents trade in the capital market. Since actions in the capital market are uncoordinated, we may view the measure of monitoring agents as being greater or less than $\Lambda^{*}$. We show below, however, that agents must believe that it is either 0 or $\Lambda^{*}$. If it is believed to be less than $\Lambda^{*}$, then it must be zero in a Nash equilibrium since each agent recognizes that her investment in monitoring is useless due to the assumption that any measure less than $\Lambda^{*}$ leads to ineffective monitoring. If it is conjectured to be greater than $\Lambda^{*}$, then there is a free-rider problem in that any agent can arbitrarily choose to not monitor without affecting the efficacy of monitoring. If the measure is believed to be precisely $\Lambda^{*}$, then the assumption that each agent is atomistic implies that the dominant strategy of each agent is not to monitor. The reason is as follows. 
If the set of monitoring agents is $Z$ (with measure $\Lambda^{*}$ ), then if agent $i \in Z$ believes that no other agent $j \in Z$ will monitor, $i$ 's best response is to not monitor either. If agent $i \in Z$ believes that all other agents $j \in Z$ will monitor, then once again her best response is not to monitor since agents $i$ 's measure is zero, and her lack of monitoring does not affect the measure of those who monitor. (This proof clarifies that if each agent had measure $\epsilon>0$, we would obtain two Nash equilibria, one in which all agents in $Z$ monitor and one in which none of them do.) Thus, monitoring agents will not trade in the financial market.

Monitoring agents will form a bank, however, since exactly $\Lambda^{*}$ monitoring agents can coalesce and invite measure $1-\Lambda^{*}$ of discretionary uninformed agents to join as nonmonitoring depositors. Given that monitoring inputs of individual agents are costlessly observed within the bank, the free-rider problem is trivially resolved. When it comes to contracting with the borrower, the bank can charge an interest factor $\left\{1+\Lambda^{*} M\right\} \eta^{-1}$ and thus recoup the cost of monitoring, $\Lambda^{*} M$, since lending without monitoring is unprofitable [see Equation (2)]. Given the competitive environment, no higher or lower rate is feasible.

Proof of Proposition 1. Follows readily from Lemmas 1 and 2.

Proof of Proposition 2. Using Equations (7) and (8) and simplifying, we can write

$$
\hat{r}(\Omega+\ell)-r_{\min }=\frac{\alpha[1-\eta]}{\eta}\left\{\frac{[1-\gamma]\{A-B[\Omega+\ell]}{\gamma[A-B \ell]+[1-\gamma][A-B\{\Omega+\ell\}]}\right\} .
$$

Substituting the above in Equation (12) and simplifying yields

$$
\begin{aligned}
V= & -M+\theta \gamma \alpha[1-\eta][1-\gamma] \\
& \times \int_{D_{\min }-\Omega}^{[2 / A]-\Omega}\left\{\frac{B^{2} \ell^{2}+\left[B^{2} \Omega-2 A B\right] \ell+A^{2}-A B \Omega}{-B \ell+A-B \Omega[1-\gamma]}\right\} d \ell .
\end{aligned}
$$

Tedious algebra enables one to simplify Equation (A1) and express it as

$$
V=-M+X \Omega^{2} .
$$

$\Omega_{1}$ is obtained by setting $V=0$ in Equation (A2) and choosing the positive root. This leads to Equation (13). Tedious algebra shows that $\partial V / \partial \Omega>0$ at $\Omega=\Omega_{1}$.

Proof of Proposition 3. We substitute Equations (7) and (8) in Equation (14) and simplify. With some tedious algebra, this leads to Equation (15). Note that since $\Omega<2 / A$, we have $A \Omega \gamma / 2<1-\{A \Omega[1-\gamma] / 2\}$, 
so that $\ln \left(\frac{[A \Omega \gamma / 2]}{1-[A \Omega\{1-\gamma\} / 2]}\right)$ is negative. Although signing $\partial V / \partial \Omega$ analytically does not seem possible, we have verified through numerical analysis that there exist sets of exogenous parameter values for which $\partial V / \partial \Omega<0$ for some $\Omega>\Omega_{1}$ and that $V$ cuts the $x$ axis only once at $\Omega^{*}$ for all $\Omega>\Omega_{1}$. The numerical analysis also helps to verify that $D_{\min }^{*}\left(\Omega^{*}\right)$ defined in Equation (10) is less than $\Omega^{*}$.

Proof of Proposition 4. The proof follows immediately from Equation (15). For any $M>0, V$ becomes negative at $\theta=0$ independently of $\Omega^{*}$. Similarly, for a given $\theta, V$ becomes negative if $M$ is sufficiently high, once again for any $\Omega^{*} \geq 0$.

Proof of Proposition 5. From Proposition 1 we know that $\partial V / \partial \Omega>0$ at $\Omega=\Omega 1>0$. Hence, an increase in $\Omega$ beyond $\Omega_{1}$ can increase an informed trader's expected profit.

Proof of Proposition 6. The proof follows immediately from comparing Equation (16) and (21). $E\left(R^{B}\right)$ is independent of $\theta$ and $E\left(R^{F}\right)$ is increasing in $\theta$. Moreover, $E\left(R^{B}\right)>E\left(R^{F}\right)=0$ at $\theta=0$ and $E\left(R^{F}\right)>E\left(R^{B}\right)$ at $\theta=1$. Thus, given continuity of $E\left(R^{F}\right)$ in $\theta$, $\exists \theta \in[\underline{\theta}, \bar{\theta}] \subset(0,1) \ni a \hat{\theta} \in(\underline{\theta}, \bar{\theta})$ can be found to satisfy $E\left(R^{F}\right)>$ $E\left(R^{B}\right) \forall \theta>\hat{\theta}$ and $E\left(R^{F}\right) \leq E\left(R^{B}\right) \forall \theta \leq \hat{\theta}$.

Proof of Proposition 7. With noisy monitoring, the zero expected profit interest factor charged by the bank, $r_{B}^{0}$, satisfies

$$
r_{B}^{0} \eta[\theta+\{1-\theta\} \xi]=1+\Lambda^{*} M
$$

which yields

$$
r_{B}^{0}=\frac{1+\Lambda^{*} M}{\eta[\theta+\{1-\theta\} \xi]} .
$$

The borrower's net payoff from bank financing is

$$
E\left(R_{0}^{B}\right)=[\theta+\{1-\theta\} \xi] \eta\left[Y-r_{B}^{0}\right]+[1-\theta][1-\xi] N .
$$

Substituting Equation (A3) in Equation (A4) and using the fact that $\eta Y>N$, we see that $\partial E\left(R_{0}^{B}\right) / \partial \theta>0$. Moreover, comparing Equation (21) and Equation (A4) also shows that $E\left(R_{0}^{B}\right)<E\left(R^{B}\right)$ for every $\theta \in[\underline{\theta}, \bar{\theta}]$.

To show that there exists a cutoff $\theta^{0}$, note that $E\left(R^{F}\right)=0$ at $\theta=0$ [see Equation (16)], and by Proposition 5 and the fact that $E\left(R_{0}^{B}\right)<$ $E\left(R^{B}\right) \forall \theta$, we know that $E\left(R^{F}\right)>E\left(R_{0}^{B}\right)$ at $\theta=\bar{\theta}$. Thus, continuity of $E\left(R^{F}\right)$ and $E\left(R_{0}^{B}\right)$ in $\theta$ guarantees that $E\left(R_{0}^{B}\right)=E\left(R^{F}\right)$ for an interior $\theta>0$ sufficiently small (assuming that $\underline{\theta}$ is small enough). This then 
establishes that $\exists \theta^{0} \in(\underline{\theta}, \bar{\theta}) \ni E\left(R^{F}\right)>E\left(R_{0}^{B}\right) \forall \theta>\theta^{0}$ and $E\left(R^{F}\right) \leq$ $E\left(R_{0}^{B}\right) \forall \theta \leq \theta^{0}$. The result that $\theta^{0}<\hat{\theta}$ follows from the result that $E\left(R_{0}^{B}\right)<E\left(R^{B}\right) \forall \theta \in[\underline{\theta}, \bar{\theta}]$.

\section{References}

Allen, F., 1990, "The Market for Information and the Origin of Financial Intermediation," Journal of Financial Intermediation, 1, 3-30.

Allen, F., 1993, "Stock Markets and Resource Allocation" in C. Mayer and X. Vives (eds.), Capital Markets and Financial Intermediation, Cambridge University Press, Cambridge.

Allen, F., and D. Gale, 1995, "A Welfare Comparison of the German and U.S. Financial Systems," European Economic Review, 39, 179-209.

Allen, F., and D. Gale, "Financial Markets, Intermediaries and Intertemporal Smoothing," forthcoming in Journal of Political Economy.

Back, K., 1993, “Asymmetric Information and Options," Review of Financial Studies, 6, 435-472.

Berlin, M., and L. Mester, 1992, "Debt Covenants and Renegotiation," Journal of Financial Intermediation, 2, 95-133.

Besanko, D., and G. Kanatas, 1993, "Credit Market Equilibrium with Bank Monitoring and Moral Hazard," Review of Financial Studies, 6, 213-232.

Bhattacharya, S., and G. Chiesa, 1995, "Financial Intermediation with Proprietary Information," Journal of Financial Intermediation, 4, 328-357.

Bhattacharya, S., and A. V. Thakor, 1993, "Contemporary Banking Theory," Journal of Financial Intermediation, 3, 2-50.

Boot, A. W., S. I. Greenbaum, and A. V. Thakor, 1993, "Reputation and Discretion in Financial Contracting," American Economic Review, 83, 1165-1183.

Boot, A. W., and A. V. Thakor, 1993a, "Security Design," Journal of Finance, 48, 1394-1378.

Boot, A. W., and A. V. Thakor, 1993b, "Self-Interested Bank Regulation," American Economic Review, 83, 206-212.

Boot, A. W., and A. V. Thakor, 1996, "Banking Scope and Financial Innovation," working paper, University of Michigan and Tinbergen Institute/University of Amsterdam, presented at the Western Finance Association Meeting, Sunriver, Oregon, June; forthcoming in Review of Financial Studies.

Boot, A. W., A. V. Thakor, and G. F. Udell, 1991, "Secured Lending and Default Risk: Equilibrium Analysis and Monetary Policy Implication," Economic Journal, 101, 458-472.

Carey, M., 1995, "Some Evidence on the Nature of Information Problems in Debt Contracting and Financial Intermediation," manuscript, Board of Governors of the Federal Reserve System, December.

Checchi, D., 1993, "Creation of Financial Markets in (Previously) Centrally Planned Economies," Journal of Banking and Finance, 17, 819-847.

Chemmanur, T. J., and P. Fulghieri, 1994, "Reputation, Renegotiation, and the Choice Between Bank Loans and Publicly Traded Debt," Review of Financial Studies, 7, 475-506.

Dewatripont, M., and E. Maskin, 1995, "Credit and Efficiency in Centralized Versus Decentralized Markets," Review of Economic Studies, 62, 541-555. 
Diamond, D., 1984, "Financial Intermediation and Delegated Monitoring," Review of Economic Studies, 51, 393-414.

Diamond, D., 1991, "Monitoring and Reputation: The Choice Between Bank Loans and Privately Placed Debt," Journal of Political Economy, 99, 688-721.

Diamond, D. W., 1993, "Seniority and Maturity of Debt Contracts," Journal of Financial Economics, 33, 341-368.

Fishman, M. J., and K. M. Hagerty, 1995, "The Incentive to Sell Financial Market Information," Journal of Financial Intermediation, 4, 95-115.

Grossman, S. J., and J. E. Stiglitz, 1980, "On the Impossibility of Informationally Efficient Markets," American Economic Review, 70, 393-408.

Hirshleifer, D., and Y. Suh, 1992, "Risk, Managerial Effort and Project Choice," Journal of Financial Intermediation, 2, 308-345.

Holmström, B., and J. Tirole, 1993, "Market Liquidity and Performance Monitoring," Journal of Political Economy, 101, 678-709.

Jacklin, C., 1987, "Demand Deposits, Trading Restrictions, and Risk Sharing," in E. C. Prescott and N. Wallace (eds.), Contractual Arangements for Intertemporal Trade, University of Minnesota Press, Minneapolis, pp. 26-47.

James, C., 1987, "Some Evidence on the Uniqueness of Bank Loans," Journal of Financial Economics, 19, 217-235.

Kane, A., and S. G. Marks, 1990, "The Delivery of Market Timing Services: Newsletters versus Market Timing Funds," Journal of Financial Intermediation, 1, 150-166.

Kane, E. J., 1989, "Changing Incentives Facing Financial-Services Regulators," Journal of Financial Services Research, 2, 263-272.

Kane, E. J., 1990, "Principal-Agent Problems in S \& L Salvage," Journal of Finance, 45, 755-764.

Lummer, S. L., and J. J. McConnell, 1989, "Further Evidence on the Bank Lending Process and the Capital Market Response to Bank Loan Agreements," Journal of Financial Economics, 25, 99-122.

Mayer, C., 1988, "New Issues in Corporate Finance," European Economic Review, 32, 1167-1188.

Mendelson, M., and J. W. Peake, 1993, "Equity Markets in Economies in Transition," Journal of Banking and Finance, 17, 913-929.

Millon, M., and A. V. Thakor, 1985, "Moral Hazard and Information Sharing: A Model of Financial Information Gathering Agencies," Journal of Finance, 40, 1403-1422.

O'Hara, M., 1993, "Real Bills Revisited: Market Value Accounting and Loan Maturity," Journal of Financial Intermediation, 3, 51-76.

Perotti, E. C., 1993, "Bank Lending in Transition Economies," Journal of Banking and Finance, 17, 1021-1032.

Rajan, R., 1992, "Insiders and Outsiders: The Choice between Informed and Arm's Length Debt," Journal of Finance, 47, 1267-1400.

Ramakrishnan, R. T. S., and A. V. Thakor, 1984, "Information Reliability and a Theory of Financial Intermediation," Review of Economic Studies, 51, 415-432.

Rock, K., 1986, “Why New Issues are Underpriced,” Journal of Financial Economics, 15, 187-212. 
Sabani, L., 1992, "Market Oriented Versus Bank Oriented Financial Systems: Incomplete Contracts and Long Term Commitments," unpublished manuscript, Universita' di Roma "La Sapienza" Dipartimento di Economia Pubblica and Trinity College, Cambridge, September.

Shockley, R., and A. V. Thakor, 1996, "The Structure of Loan Commitment Contracts: Data, Theory, and Tests," working paper, Indiana University and University of Michigan, September; forthcoming in Journal of Money, Credit and Banking.

Thakor, A. V., and P. Wilson, 1995, "Capital Requirements, Loan Renegotiation and the Borrower's Choice of Financing Source," Journal of Banking and Finance, 19, 693-712.

Van Wijnbergen, S., 1994, "The Role of Banks in Corporate Restructuring: The Polish Example," working paper, CEPR, London, November.

von Thadden, E. L., 1995, "Long-Term Contracts, Short-Term Investment and Monitoring," Review of Economic Studies, 62, 557-575.

Wilson, P., 1994, "Public Ownership, Delegated Project Selection and Corporate Financial Policy," working paper, Indiana University, February.

Yosha, O., 1995, "Information Disclosure Costs and the Choice of Financing Source," Journal of Financial Intermediation, 4, 3-20. 
http://www.jstor.org

\section{LINKED CITATIONS}

- Page 1 of 4 -

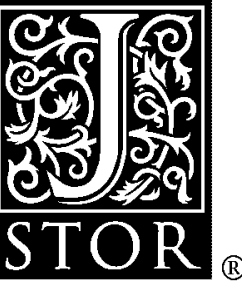

You have printed the following article:

Financial System Architecture

Arnold W. A. Boot; Anjan V. Thakor

The Review of Financial Studies, Vol. 10, No. 3. (Autumn, 1997), pp. 693-733.

Stable URL:

http://links.jstor.org/sici?sici=0893-9454\%28199723\%2910\%3A3\%3C693\%3AFSA\%3E2.0.CO\%3B2-4

This article references the following linked citations. If you are trying to access articles from an off-campus location, you may be required to first logon via your library web site to access JSTOR. Please visit your library's website or contact a librarian to learn about options for remote access to JSTOR.

\section{[Footnotes]}

\section{${ }^{3}$ On the Impossibility of Informationally Efficient Markets}

Sanford J. Grossman; Joseph E. Stiglitz

The American Economic Review, Vol. 70, No. 3. (Jun., 1980), pp. 393-408.

Stable URL:

http://links.jstor.org/sici?sici=0002-8282\%28198006\%2970\%3A3\%3C393\%3AOTIOIE\%3E2.0.CO\%3B2-6

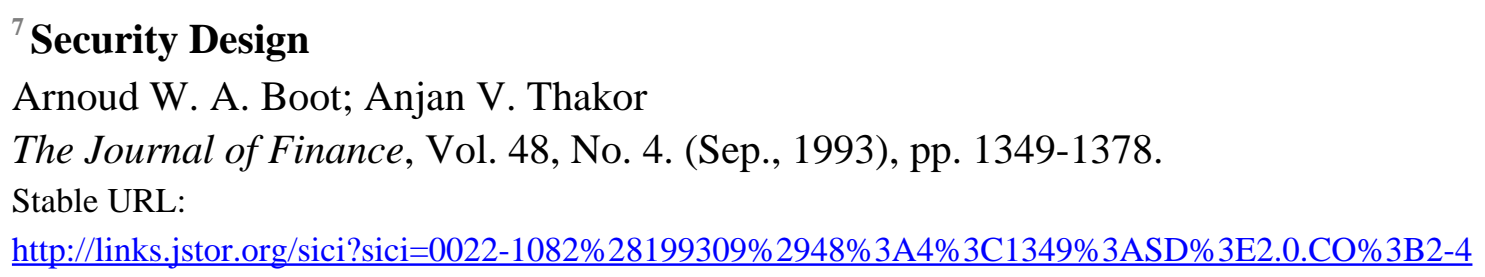

\section{${ }^{19}$ Information Reliability and a Theory of Financial Intermediation}

Ram T. S. Ramakrishnan; Anjan V. Thakor

The Review of Economic Studies, Vol. 51, No. 3. (Jul., 1984), pp. 415-432.

Stable URL:

http://links.jstor.org/sici?sici=0034-6527\%28198407\%2951\%3A3\%3C415\%3AIRAATO\%3E2.0.CO\%3B2-8

\footnotetext{
${ }^{19}$ Moral Hazard and Information Sharing: A Model of Financial Information Gathering Agencies

Marcia H. Millon; Anjan V. Thakor

The Journal of Finance, Vol. 40, No. 5. (Dec., 1985), pp. 1403-1422.

Stable URL:

http://links.jstor.org/sici?sici=0022-1082\%28198512\%2940\%3A5\%3C1403\%3AMHAISA\%3E2.0.CO\%3B2-U

NOTE: The reference numbering from the original has been maintained in this citation list.
} 
http://www.jstor.org

\title{
LINKED CITATIONS
}

- Page 2 of 4 -

\author{
${ }^{20}$ Reputation and Discretion in Financial Contracting \\ Arnoud W. A. Boot; Stuart I. Greenbaum; Anjan V. Thakor \\ The American Economic Review, Vol. 83, No. 5. (Dec., 1993), pp. 1165-1183. \\ Stable URL: \\ http://links.jstor.org/sici?sici=0002-8282\%28199312\%2983\%3A5\%3C1165\%3ARADIFC\%3E2.0.CO\%3B2-C
}

\section{References}

\section{Asymmetric Information and Options}

Kerry Back

The Review of Financial Studies, Vol. 6, No. 3. (1993), pp. 435-472.

Stable URL:

http://links.jstor.org/sici?sici=0893-9454\%281993\%296\%3A3\%3C435\%3AAIAO\%3E2.0.CO\%3B2-\%23

\section{Credit Market Equilibrium with Bank Monitoring and Moral Hazard}

David Besanko; George Kanatas

The Review of Financial Studies, Vol. 6, No. 1. (1993), pp. 213-232.

Stable URL:

http://links.jstor.org/sici?sici=0893-9454\%281993\%296\%3A1\%3C213\%3ACMEWBM\%3E2.0.CO\%3B2-3

\section{Reputation and Discretion in Financial Contracting}

Arnoud W. A. Boot; Stuart I. Greenbaum; Anjan V. Thakor

The American Economic Review, Vol. 83, No. 5. (Dec., 1993), pp. 1165-1183.

Stable URL:

http://links.jstor.org/sici?sici=0002-8282\%28199312\%2983\%3A5\%3C1165\%3ARADIFC\%3E2.0.CO\%3B2-C

\section{Security Design}

Arnoud W. A. Boot; Anjan V. Thakor

The Journal of Finance, Vol. 48, No. 4. (Sep., 1993), pp. 1349-1378.

Stable URL:

http://links.jstor.org/sici?sici=0022-1082\%28199309\%2948\%3A4\%3C1349\%3ASD\%3E2.0.CO\%3B2-4

NOTE: The reference numbering from the original has been maintained in this citation list. 
http://www.jstor.org

\section{LINKED CITATIONS}

- Page 3 of 4 -

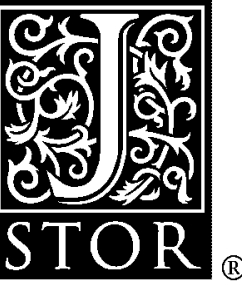

\section{Self-Interested Bank Regulation}

Arnoud W. A. Boot; Anjan V. Thakor

The American Economic Review, Vol. 83, No. 2, Papers and Proceedings of the Hundred and Fifth Annual Meeting of the American Economic Association. (May, 1993), pp. 206-212.

Stable URL:

http://links.jstor.org/sici?sici=0002-8282\%28199305\%2983\%3A2\%3C206\%3ASBR\%3E2.0.CO\%3B2-L

Secured Lending and Default Risk: Equilibrium Analysis, Policy Implications and Empirical Results

Arnoud W. A. Boot; Anjan V. Thakor; Gregory F. Udell

The Economic Journal, Vol. 101, No. 406. (May, 1991), pp. 458-472.

Stable URL:

http://links.jstor.org/sici?sici=0013-0133\%28199105\%29101\%3A406\%3C458\%3ASLADRE\%3E2.0.CO\%3B2-D

\section{Reputation, Renegotiation, and the Choice between Bank Loans and Publicly Traded Debt}

Thomas J. Chemmanur; Paolo Fulghieri

The Review of Financial Studies, Vol. 7, No. 3. (Autumn, 1994), pp. 475-506.

Stable URL:

http://links.jstor.org/sici?sici=0893-9454\%28199423\%297\%3A3\%3C475\%3ARRATCB\%3E2.0.CO\%3B2-K

\section{Credit and Efficiency in Centralized and Decentralized Economies}

M. Dewatripont; E. Maskin

The Review of Economic Studies, Vol. 62, No. 4. (Oct., 1995), pp. 541-555.

Stable URL:

http://links.jstor.org/sici?sici=0034-6527\%28199510\%2962\%3A4\%3C541\%3ACAEICA\%3E2.0.CO\%3B2-R

Financial Intermediation and Delegated Monitoring

Douglas W. Diamond

The Review of Economic Studies, Vol. 51, No. 3. (Jul., 1984), pp. 393-414.

Stable URL:

http://links.jstor.org/sici?sici=0034-6527\%28198407\%2951\%3A3\%3C393\%3AFIADM\%3E2.0.CO\%3B2-1

On the Impossibility of Informationally Efficient Markets

Sanford J. Grossman; Joseph E. Stiglitz

The American Economic Review, Vol. 70, No. 3. (Jun., 1980), pp. 393-408.

Stable URL:

http://links.jstor.org/sici?sici=0002-8282\%28198006\%2970\%3A3\%3C393\%3AOTIOIE\%3E2.0.CO\%3B2-6

NOTE: The reference numbering from the original has been maintained in this citation list. 
http://www.jstor.org

\section{LINKED CITATIONS \\ - Page 4 of 4 -}

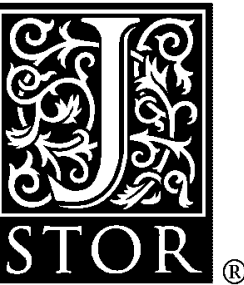

\section{Principal-Agent Problems in S\&L Salvage}

Edward J. Kane

The Journal of Finance, Vol. 45, No. 3, Papers and Proceedings, Forty-ninth Annual Meeting, American Finance Association, Atlanta, Georgia, December 28-30, 1989. (Jul., 1990), pp. 755-764. Stable URL:

http://links.jstor.org/sici?sici=0022-1082\%28199007\%2945\%3A3\%3C755\%3APPISS\%3E2.0.CO\%3B2-S

\section{Moral Hazard and Information Sharing: A Model of Financial Information Gathering Agencies}

Marcia H. Millon; Anjan V. Thakor

The Journal of Finance, Vol. 40, No. 5. (Dec., 1985), pp. 1403-1422.

Stable URL:

http://links.jstor.org/sici?sici=0022-1082\%28198512\%2940\%3A5\%3C1403\%3AMHAISA\%3E2.0.CO\%3B2-U

\section{Insiders and Outsiders: The Choice between Informed and Arm's-Length Debt}

Raghuram G. Rajan

The Journal of Finance, Vol. 47, No. 4. (Sep., 1992), pp. 1367-1400.

Stable URL:

http://links.jstor.org/sici?sici=0022-1082\%28199209\%2947\%3A4\%3C1367\%3AIAOTCB\%3E2.0.CO\%3B2-F

\section{Information Reliability and a Theory of Financial Intermediation}

Ram T. S. Ramakrishnan; Anjan V. Thakor

The Review of Economic Studies, Vol. 51, No. 3. (Jul., 1984), pp. 415-432.

Stable URL:

http://links.jstor.org/sici?sici=0034-6527\%28198407\%2951\%3A3\%3C415\%3AIRAATO\%3E2.0.CO\%3B2-8

\section{Long-Term Contracts, Short-Term Investment and Monitoring}

Ernst-Ludwig Von Thadden

The Review of Economic Studies, Vol. 62, No. 4. (Oct., 1995), pp. 557-575.

Stable URL:

http://links.jstor.org/sici?sici=0034-6527\%28199510\%2962\%3A4\%3C557\%3ALCSIAM\%3E2.0.CO\%3B2-T

NOTE: The reference numbering from the original has been maintained in this citation list. 